\title{
Proteasome inhibition and its therapeutic potential in multiple myeloma
}

\author{
This article was published in the following Dove Press journal: \\ Biologics:Targets \& Therapy \\ 27 September 2010 \\ Number of times this article has been viewed
}

\section{Ajai Chari' \\ Amitabha Mazumder ${ }^{2}$ \\ Sundar Jagannath' \\ 'Mount Sinai School of Medicine, New York, NY, USA; ${ }^{2}$ New York University School of Medicine, New York, NY, USA}

Correspondence: Ajai Chari Mt Sinai Hospital - Multiple Myeloma Program, One Gustave L Levy Place, Box I I85, New York, NY I0029, USA

Tel + I 2/2-24I-7873

Fax + I 2|2-24|-3908

Email ajai.chari@mssm.edu

\begin{abstract}
Due to an unmet clinical need for treatment, the first in class proteasome inhibitor, bortezomib, moved from drug discovery to FDA approval in multiple myeloma in an unprecedented eight years. In the wake of this rapid approval arose a large number of questions about its mechanism of action and toxicity as well as its ultimate role in the treatment of this disease. In this article, we briefly review the preclinical and clinical development of the drug as the underpinning for a systematic review of the large number of clinical trials that are beginning to shed some light on the full therapeutic potential of bortezomib in myeloma. We conclude with our current understanding of the mechanism of action of this agent and a discussion of the novel proteasome inhibitors under development, as it will be progress in these areas that will ultimately determine the true potential of proteasome inhibition in myeloma.
\end{abstract}

Keywords: bortezomib, multiple myeloma

\section{The proteasome}

The proteasome is a large, hollow cylindrical multi-enzymatic complex that is present in both the cytoplasm and the nucleus of all eukaryotic cells. It is necessary for the degradation of intracellular proteins in eukaryotic cells whereas extracellular/ transmembrane proteins are typically degraded by the aggresome/lysosomal pathway. ${ }^{1}$ The proteins degraded by the former pathway are involved in signal transduction pathways that regulate cell growth and proliferation including: cell-cycle-regulatory proteins (cyclins A, B, D, and E; p21 and p27), the tumor suppressor p53, NF- $\mathrm{B}$, and adhesion molecules. ${ }^{4}$

The formation of the $26 \mathrm{~S}$ proteasome occurs in an ATP dependent fashion, when a $20 \mathrm{~S}$ catalytic core is capped by a $19 \mathrm{~S}$ regulatory subunit at both ends (see Figure 1A). ${ }^{1}$ The lysine residues of those proteins targeted for degradation are covalently modified with a polyubquitin protein chain, with each ubiquitin tag consisting of a 76 amino acid polypeptide. The ubiquitin chain is recognized by the lid-like structure of the19S subunit and then removed. The target protein is then denatured in an energy dependent manner by the 6 ATPases at the base of the 19S subunit and threaded into the center of the $20 \mathrm{~S}$ subunit. ${ }^{2}$

As shown in Figure 1B, the 20S subunit is itself comprised of four rings, $2 \alpha$ and 2 $\beta$ subunits. Within the channel at the center, threonine residues of the indicated $\beta$ units wield catalytic activity comparable to three enzymes: chymotrypsin $(\beta 5), \operatorname{trypsin}(\beta 2)$, and post-glutamyl peptide hydrolase $(\beta 1)$. 


\section{Preclinical development of bortezomib}

In 1993, the company Myogenics was founded by Alfred Goldberg to decrease muscle wasting/cachexia by inhibiting

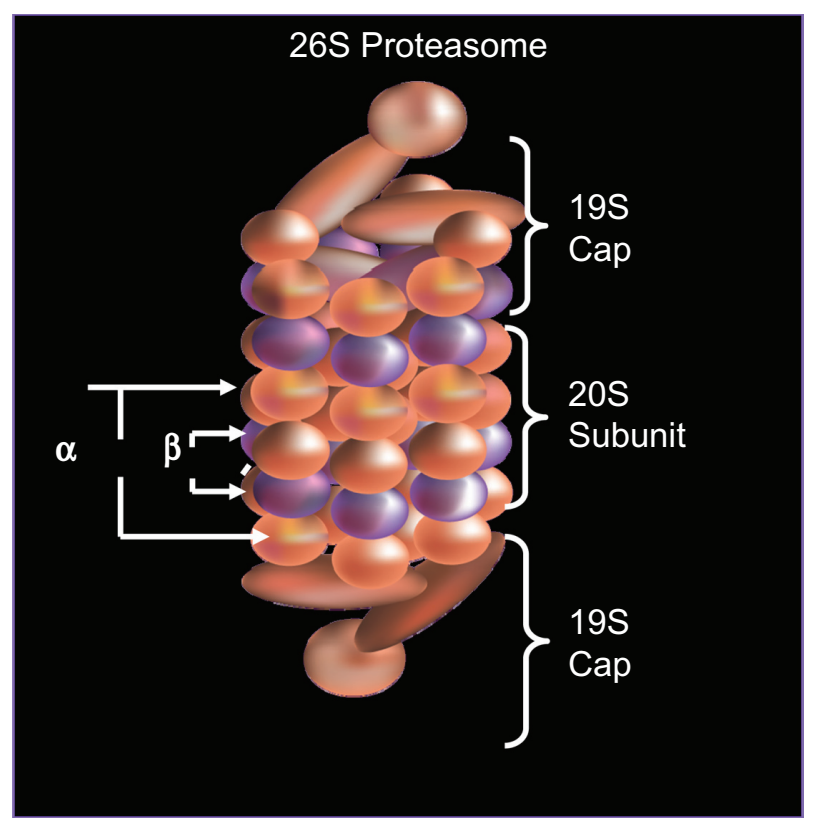

Figure IA Structure of $26 \mathrm{~S}$ proteasome: the $26 \mathrm{~S}$ proteasome is formed when the $20 \mathrm{~S}$ catalytic core is capped by I9S regulatory subunits at both ends in an ATP dependent fashion.

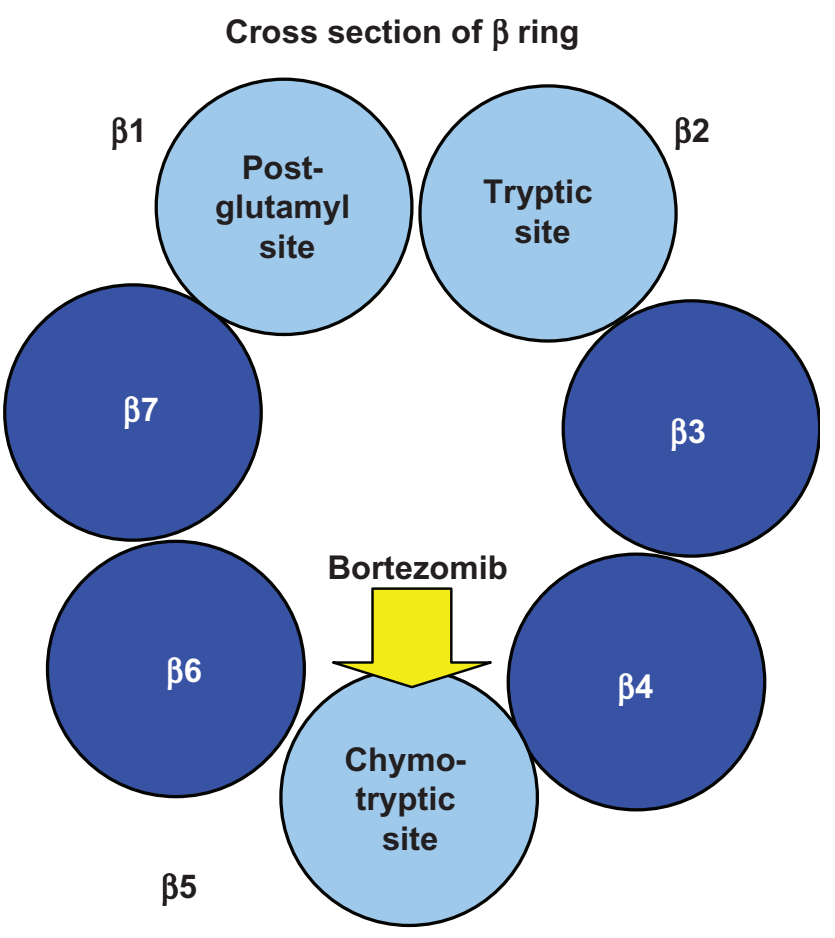

Figure IB Cross section of the $\beta$ ring of the 20S subunit of the proteasome: the post-glutamyl, tryptic, and chymotryptic sites are comprised of the threonine residues of the $\beta 1, \beta 2$, and $\beta 5$ subunits respectively. Bortezomib inhibits the chymotryptic site. the ubiquitin-proteasome pathway. A team of enzymologists created the first inhibitors of the proteasome: peptide aldehyde analogs of the proteasome's chymotrypsin-like substrates. Chemists then created a dipeptide boronic acid analog that would eventually come to be known as bortezomib (Figure 2). ${ }^{3}$

When applied to the National Cancer Institute's 60-cell line screen, bortezomib demonstrated potent growth inhibition against a broad range of tumor types. ${ }^{5}$ Importantly, confirmation was also obtained that the intended biologic target was being inhibited. Additional studies with human myeloma cell lines and freshly isolated from myeloma patients confirmed that bortezomib not only inhibited tumor proliferation but also induced apoptosis and overcame drug resistance. ${ }^{6}$

The growth inhibition of bortezomib was extended to the in vivo setting using a human plasmacytoma xenograft mouse model. Relative to controls, bortezomib treatment resulted in improved overall survival. ${ }^{7}$ A fluorogenic pharamacodynamic assay was developed to measure the relative chymotryptic and tryptic activities of the proteasome in peripheral blood mononuclear cells. ${ }^{8}$ This assay showed that bortezomib-mediated inhibition of the chymotrypsin-like activity of the $26 \mathrm{~S}$ mammalian proteasome (Figure 1B) was dose-dependent and reversible, ${ }^{7}$ thus helping guide dosing and optimize dose escalation in phase I studies.

\section{Clinical development of bortezomib - relapsed/ refractory multiple myeloma}

In a phase I trial among patients with advanced hematological malignancies, bortezomib was noted to have activity in

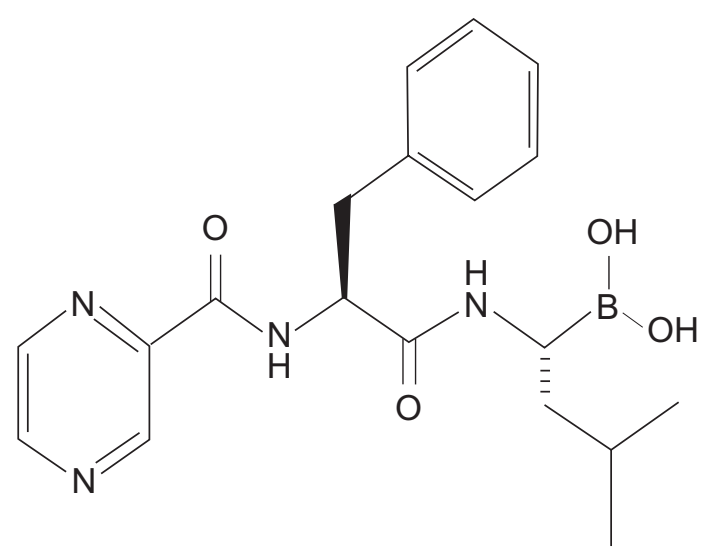

Figure 2 Chemical structure of bortezomib. 
patients with refractory myeloma; among nine patients with multiple myeloma antitumor activity was noted in almost all patients including 1 patient achieving a complete response. ${ }^{4}$ A subsequent, large, multicenter phase II trial involving 202 patients with relapsed, refractory myeloma yielded a $35 \%$ overall response rate which was comprised of a $4 \%$ complete remission (CR), $6 \%$ near CR, $18 \%$ partial remission (PR), and 7\% minimal response (MR). ${ }^{9}$ It was on the basis of this trial in large part, that bortezomib was approved by the United States Food and Drug Administration (FDA) in 2003 , thus resulting in a remarkably short 8 years from drug discovery to FDA approval.

The phase III Assessment of Proteasome Inhibition for Extending Remissions (APEX) study compared bortezomib $\left(1.3 \mathrm{mg} / \mathrm{m}^{2}\right.$ on days $1,4,8$, and 11 by intravenous push for eight 3 -week cycles) to high dose dexamethasone (40 mg days $1-4,9-12$, and $17-20$ orally for four 5 -week cycles and then days 1-4 for five 4-week cycles) in 669 patients with relapsed multiple myeloma. The study was halted on interim analysis because bortezomib treatment resulted in higher response rates (38 vs 18\%), longer time to progression (6.22 months vs 3.49 months), and improved overall survival. The median time to response was 43 days in both groups. ${ }^{10}$ In an updated analysis, based on a median follow up of 22 months, the median overall survival was 29.8 vs 23.7 months $(P=0.0272)$ despite a $62 \%$ crossover rate from dexamethasone to boretzomib. ${ }^{11}$ As shown in Figure 3, a comparison of the Grade 3/4 adverse events in each arm reveals that bortezomib treatment is associated with an increased incidence of thrombocytopenia, neutropenia, peripheral neuropathy, and diarrhea. ${ }^{10}$ The thrombocytopenia and neuropathy are discussed in further detail below. Despite these toxicities, a prospective comparsion of health-related quality of life found improved outcomes with bortezomib. ${ }^{12}$ Of note, subgroup analysis has also found no difference in safety or efficacy in patients with varying degrees of renal insufficiency. ${ }^{13}$

Bortezomib therapy also appears to have beneficial effects on the bone. When alkaline phosphatase levels were compared with responders and nonresponders in the APEX study, the most powerful predictor of a response was a $25 \%$ increase in alkaline phosphatase at week $6(P<0.0001)$ (Figure 4$).{ }^{14}$ Laboratory work has confirmed the ability of bortezomib to not only inhibit osteclast mediated bone destruction, but also directly induce bone formation. ${ }^{15,16}$ Interestingly, as shown in Figure 4, the increase in alkaline phosphatase was not observed on the dexamethasone arm, even in the responders. ${ }^{14}$ This increase has also been recently found to be associated with improved time to progression. ${ }^{17}$

As the safety and efficacy results for bortezomib monotherapy were accumulating, combination therapy was being explored in the preclinical setting. Hideshima et al found that the growth inhibitory effects of bortezomib and dexamethasone on a myeloma cell line were additive (Figure 5A). ${ }^{6}$ Ma et al found that the addition of a noncytotoxic dose of bortezomib to chemotherapeutic agents could increase the sensitivity of chemoresistant myeloma cells by 100,000 to $1,000,000$-fold without affecting normal hematopoietic cells (Figure 5B). ${ }^{18}$

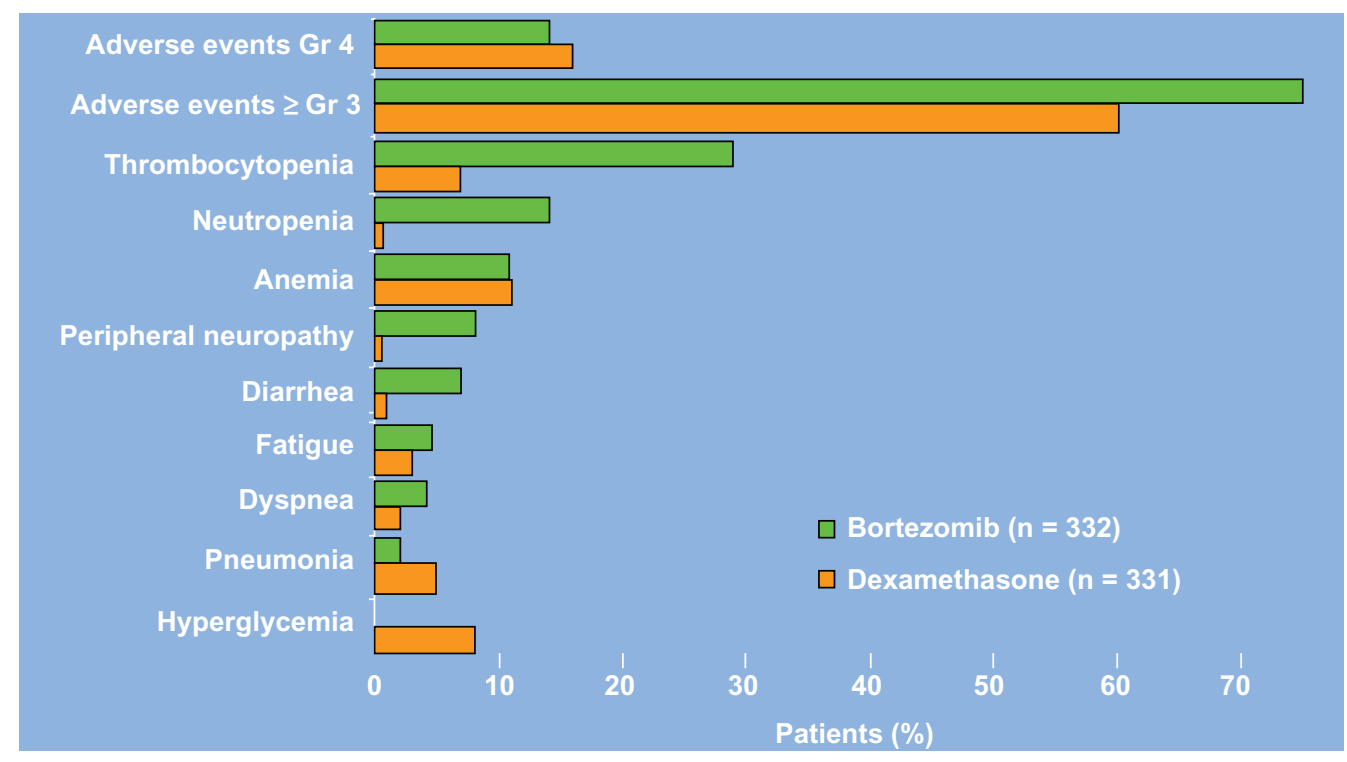

Figure 3 Grade 3/4 adverse events of bortezomib and dexamethasone in the APEX trial. 


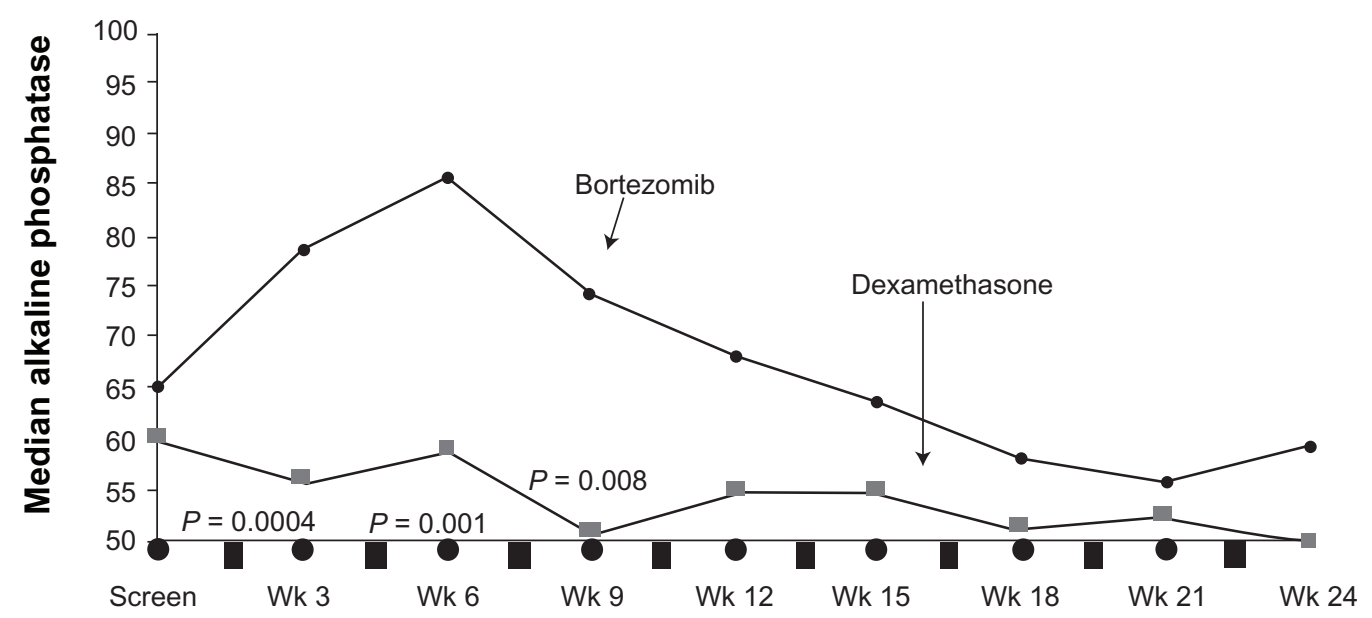

Duration of treatment

Figure 4 Median levels of alkaline phosphatase levels of patients with multiple myeloma who responded to treatment with bortezomib and dexamethasone in the APEX trial. Reproduced with permission from Zangari M, Esseltine D, Lee CK, et al. Response to bortezomib is associated to osteoblastic activation in patients with multiple myeloma. BrJ Haematol. 2005; I II(I):7I-73.14 Copyright (C) 2005 John Wiley and Sons.

The largest published phase III clinical trial combining bortezomib with another chemotherapeutic agent randomized 646 myeloma patients with 2 or more lines of prior therapy to receive either the standard dose/schedule of bortezomib alone or with liposomal doxorubicin (PLD) on Day 4. The combination therapy was associated with a higher incidence of grade $3 / 4$ events 80 vs $64 \%$ (due to myelosuppression, constitutional and gastrointestinal symptoms, and hand foot syndrome). There was also no significant difference in response rates. However, the time to progression (9.3 vs 6.5 months, $P=0.000004$ ) and overall survival at 15 months (76\% vs $65 \%, P=0.03$ ) both favored bortezomib with PLD. ${ }^{19}$

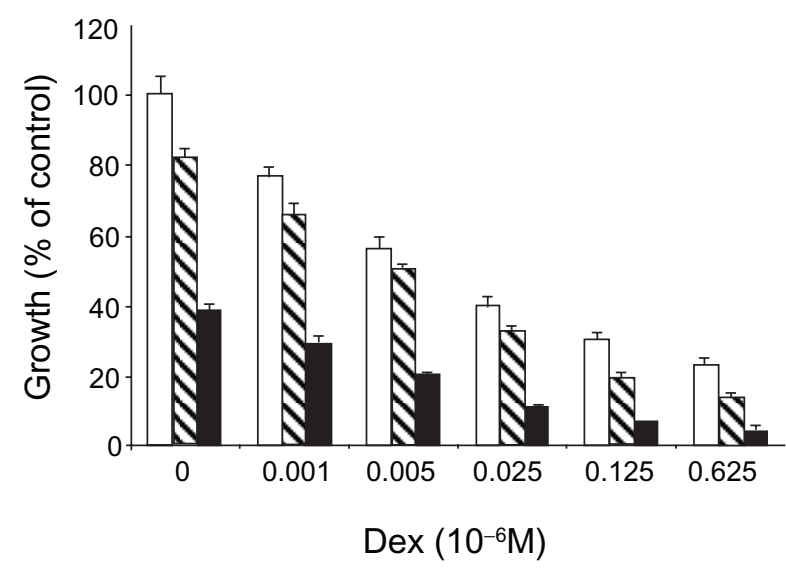

Figure 5A Dexamethasone sensitive myeloma cells (MM.IS) cultured with $0.00 \mathrm{I}$ to $0.625 \times 10^{-6} \mathrm{M}$. Dexamethasone in control media $(\square)$ and with bortezomib 0.0025 $(\mathbf{N})$ or $0.005(\square) \times 10^{-6}$ M. Reproduced with permission from Hideshima T, Richardson P, Chauhan D, et al.The proteasome inhibitor PS-34I inhibits growth, induces apoptosis, and overcomes drug resistance in human multiple myeloma cells. Cancer Res. 200 I;6I (7): 307I-3076. ${ }^{6}$ Copyright $\odot 2001$ American Association for Cancer Research.
This steroid sparing regimen is an excellent treatment option especially for those patients intolerant of steroids due to psychosis or brittle diabetes.

The proteasome inhibitor bortezomib has now been studied in combination with each of the three other classes of drugs with activity in myeloma: steroids, immunomodulatory agents (IMids), and conventional chemotherapeutics (anthracyclines and alkylating agents). For those phase I/II studies with 30 or more evaluable patients, summaries of the recent response data of doublet (Table 1), triplet (Table 2), and multiagent (Table 3) permutations of the four classes of drugs in relapsed/refractory myeloma are shown in the indicated tables.

\section{Bortezomib in previously untreated multiple myeloma}

The only published phase III study of bortezomib in untreated myeloma is the Velcade as Initial Standard Therapy in Multiple Myeloma: Assessment with Melphalan Prednisone (VISTA) study. In this study, 682 nontransplant eligible patients with untreated myeloma were randomized to receive either melphalan and prednisone alone (MP) or with bortezomib (VMP) at the doses and schedule shown in Figure 6.

Overall response rate for VMP was $71 \%$ vs $35 \%$ for MP with a very impressive CR rate of $30 \%$ vs $4 \%(P<0.001$ for both comparisons). Of note, a $30 \% \mathrm{CR}$ rate compares very favorably to the $\mathrm{CR}$ rates obtained for patients who receive high dose melphalan chemotherapy with autologous stem cell rescue (for which none of the patients in the VISTA study were eligible). With a median follow up of 16.3 months, the 

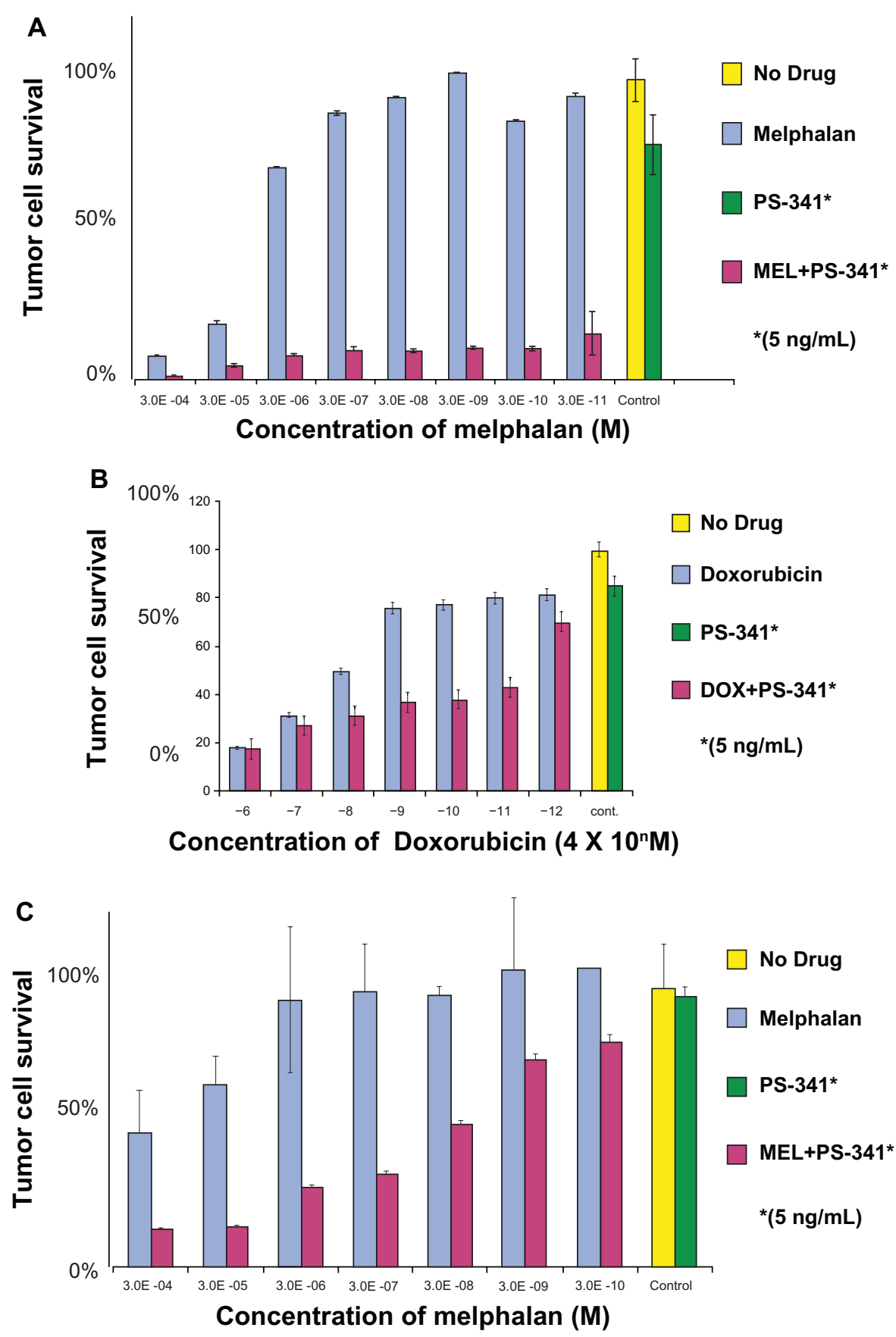

Figure 5B The addition of bortezomib to chemotherapeutic agents results in synergistic cytotoxicity in multiple myeloma cells: A) Melphalan-resistant cell line (RPMI8228/LR) treated for 24 hours with varying concentrations of melphalan alone or in combination with a noncytotoxic dose of bortezomib; B) Doxorubicin-resistant cell line (U266/dox4) treated for 24 hours with varying concentrations of doxorubicin alone or in combination with a noncytotoxic dose of bortezomib. C) Fresh myeloma cells treated with varying concentrations of melphalan alone or in combination with a noncytotoxic dose of bortezomib. Reproduced with permission from Ma MH,Yang $\mathrm{HH}$, Parker $\mathrm{K}$, et al.The proteasome inhibitor PS-34I markedly enhances sensitivity of multiple myeloma tumor cells to chemotherapeutic agents. Clin Cancer Res. 2003;9(3): I I36-II44. ${ }^{18}$ Copyright @ 2003 American Association for Cancer Research.

hazard ratio for overall survival for the VMP group was 0.61 $(P=0.008) \cdot .^{34}$

All of the following efficacy outcomes were also significantly better for the VMP group relative to MP: median time to first response (1.4 vs 4.2 months), duration of response (20 vs 13 months), and treatment-free interval
(17 months vs 9 months). The improved outcomes were seen in all subgroups, including age $>75$, creatinine clearance $<60$, and high risk cytogenetics (translocation ( $\mathrm{t})(4 ; 14), \mathrm{t}(14,16)$, or chromosome 17 deletion) ${ }^{34}$ Of note, the lack of effect of high risk cytogenetics on efficacy with borezomib-based regimens has been a consistent finding across all front line studies. ${ }^{34-37}$ 
Table I Clinical trials of bortezomib in doublet-drug combination regimens

\begin{tabular}{llllll}
\hline Study & Phase & Regimen & n & CR/nCR & ORR \\
\hline Berenson et al $^{20}$ & $\mathrm{I} / / \mathrm{l}$ & Vel/Mel & 46 & $15 \%$ & $70 \%$ \\
Popat et al $^{21}$ & $\mathrm{I} / \mathrm{ll}$ & Vel/Mel \pm Dex & 53 & $23 \%$ & $68 \%$ \\
Pineda-Roman et al $^{22}$ & $\mathrm{I} / / \mathrm{l}$ & $\mathrm{VT} \pm$ Dex & 85 & $22 \%$ & $63 \%$ \\
\hline
\end{tabular}

Abbreviations: $\mathrm{n}$, number of evaluable patients; $\mathrm{Cr}$, complete remission; $\mathrm{nCR}$, near complete remission; ORR, overall response rate; Vel/Mel, velcade, melphalan; VT, velcade, thalidomide.

Table 2 Clinical trials of bortezomib in triplet-drug combination regimens

\begin{tabular}{|c|c|c|c|c|c|}
\hline Study & Phase & Regimen & $n / \mathbf{N}$ & CR/nCR & ORR \\
\hline Reece et $\mathrm{a}^{23}$ & $\mid / / I$ & VCP & $37 / 37$ & $27 \%$ & $68 \%$ \\
\hline Kropff et a $\left.\right|^{24}$ & II & VCD & $50 / 54$ & $16 \%$ CR & $82 \%$ \\
\hline Hajek et $\mathrm{a}^{25}$ & II & & $39 / 40$ & - & $51 \%$ \\
\hline Lee et $\mathrm{a}^{26}$ & II & $\mathrm{PAD} \rightarrow \mathrm{TD}$ & $30 / 39$ & $70 \%$ & $90 \%$ \\
\hline Palumbo et $\mathrm{al}^{27}$ & & PAD & $64 / 64$ & $25 \%$ & $67 \%$ \\
\hline Richardson et $\mathrm{al}^{28}$ & II & VRD & $62 / 24$ & $21 \%$ & $84 \%(\geq M R)$ \\
\hline Poensich et $\mathrm{al}^{29}$ & II & VBP & $46 / 46$ & $15 \%$ & $61 \%$ \\
\hline
\end{tabular}

Abbreviations: $\mathrm{n} / \mathrm{N}$, number of evaluable patients/total number of enrolled patients; VCP, bortezomib, cyclophosphamide, prednisone; VCD, bortezomib, cyclophosphamide, dex; PAD, bortezomib, adriamycin, dex;TD, thalidomide, dex; VRD: bortezomib, lenalidomide, dex; VBP, bortezomib, bendamustine, prednisone.

Table 3 Clinical trials of bortezomib in multiple drug combination regimens

\begin{tabular}{llllll}
\hline Study & Phase & Regimen & $\mathbf{n}$ & Cr/nCR & ORR \\
\hline Palumbo et al $^{30}$ & I/II & VMPT & $30 / 30$ & $44 \%$ & $67 \%$ \\
Terpos et al $^{31}$ & II & VMDT & $62^{\mathrm{a}}$ & - & $66 \%$ \\
Ciolli et al $^{32}$ & II & VTDD & $42 / 42$ & $52 \%$ & $74 \%$ \\
Kim et al $^{33}$ & II & VCTD & $56 / 35$ & $53 \%$ CR & $92 \%$ \\
\hline
\end{tabular}

${ }^{a}$ number of evaluable patients unknown.

Abbreviations: $\mathrm{n}$, number of evaluable patients; $\mathrm{Cr}$, complete remission; $\mathrm{nCR}$, near complete remission; ORR, overall response rate; VMPT, bortezomib, melphalan, prednisone, thalidomide;VMDT, bortezomib, melphalan, dex, thalidomide;VTDD, bortezomib, thalidomide, dex, liposomal doxorubicin; VCTD, bortezomib, cyclophosphamide, thalidomide, dex.

Toxicities $\geq$ Grade 3 that were higher in the VMP arm included peripheral neuropathy (14 vs $0 \%$ ), nausea/ vomiting/diarrhea, fatigue/asthenia, and zoster. Herpes zoster was observed in $14 \%$ of VMP patients vs $4 \%$ in MP, but among patients receiving antiviral prophylaxis, the rate was $3 \% .^{34}$

Of note, a recent analysis of varicella zoster virus (VZV) reactivation in the APEX study also found a significantly increased incidence in patients receiving bortezomib relative to dexamethasone $13 \%$ vs $5 \%, P=0.0002 .{ }^{38}$ Antiviral prophylaxis is therefore recommended for all myeloma patients receiving bortezomib based regimens. A variety of agents and regimens have been used including acyclovir $400 \mathrm{mg}$ daily, valacyclovir 250 or $500 \mathrm{mg}$ daily, famciclovir $500 \mathrm{mg}$ daily. ${ }^{39,40}$ Doses should be decreased in the setting of renal insufficiency as the metabolites of these drugs can accumulate and cause profound neuropsychiatric changes ${ }^{41,42}$ Finally, the varicella vaccine, which contains live attenuated virus, is not licensed for use in patients with neoplasms affecting the bone marrow or lymphatic systems. ${ }^{43}$

Additional follow up data presented recently indicated that despite the fact that $43 \%$ of MP patients subsequently received bortezomib upon progression, intention to treat analysis still demonstrated increased overall survival for the VMP group. Moreover, there was no difference in response to IMiD-based second line treatments between the two groups. ${ }^{44}$ The results of the VISTA study therefore demonstrate clearly improved efficacy with VMP without any adverse long term consequences of upfront bortezomib based regimens.

There are also several large phase III studies ongoing evaluating the use of bortezomib as induction therapy prior to stem cell transplantation (see Table 4). The Franchophone Myeloma Intergroup (IFM) 2005-01 study randomized 482 patients to receive either bortezomibdexamethasone (Vel-Dex) or the traditional VAD. Of the 442 evaluable patients, the CR rates were $10 \%$ vs $3 \%$, CR + near CR $19 \%$ vs $8 \%$, and $\geq$ PR 83 vs $66 \%$ without any impairment in stem cell harvest. Moreover, the higher quality of responses persisted after the first melphalan $200 \mathrm{mg} / \mathrm{m}^{2}$ followed by autologous stem cell rescue, with $\mathrm{CR} /$ near CR rates of 40 vs $22 \%, P=0.0001 .{ }^{36}$ Preliminary data from two other phase III studies comparing bortezomib in combination with doxorubicin and dexamethasone (PAD) to traditional $\mathrm{VAD}^{37}$ and bortezomib, thalidomide, and dexamethasone (VTD) to $\mathrm{TD}^{35}$ also found improved $\mathrm{CR} / \mathrm{nCR}$ rates $(23 \%$ vs $9 \%, P<0.015$ and $55 \%$ vs $32 \%$, $P<0.001$ respectively) after autologous stem cell transplantation.

These improvements in CR rates after transplant with bortezomib based induction therapies have clinical significance. Two large published phase III studies comparing single vs tandem autologous stem cell transplants in myeloma found that patients who did not achieve a $\mathrm{CR} /$ near $\mathrm{CR}$ after the first autologus stem cell transplant were the ones that could benefit from a second SCT. ${ }^{48,49}$ Therefore, the higher $\mathrm{CR}$ rates being obtained with novel induction regimens may obviate the need for a second autologous 
Table 4 Summary of phase III trials in previously untreated MM

\begin{tabular}{|c|c|c|c|c|c|c|}
\hline Trial & Regimen & $\mathbf{N} / \mathbf{N}^{\dagger}$ & CR/nCR & VGPR & PR & ORR \\
\hline IFM 2005-0I: Harousseau et al $\left.\right|^{36}$ & Vel/Dex (vs VAD) & $424 / 482$ & $19 \%($ vs $8 \%)$ & $24 \%$ & $43 \%$ & $83 \%$ \\
\hline HOVON-655/GMMG-H4: Sonneveld et a $\left.\right|^{37}$ & PAD (vs VAD) & $300 / 300$ & $23 \%$ (vs $9 \%)$ & $37 \%$ & - & $83 \%$ \\
\hline GIMEMA: Cavo et $\mathrm{a}^{35}$ & VTD (vs TD) & $460 / 474$ & $55 \%$ (vs $32 \%$ ) & $30 \%$ & $32 \%$ & $94 \%$ \\
\hline PETHEMA/GEM: Rosinol et a $\left.\right|^{47}$ & VTD vs (TD vs VBMCP/VBAD/Vel) & $183 / 190$ & $41 \%$ (vs $12 \%$ vs $28 \%$ ) & - & $39 \%$ & $80 \%$ \\
\hline VISTA: San Miguel et $\mathrm{a}^{34,44}$ & VMP (vs MP) & $668 / 682$ & $30 \%$ CR (vs $4 \%$ ) & $\mathrm{N} / \mathrm{A}$ & $40 \%$ & $71 \%$ \\
\hline GEM05MAS65: Mateos et al ${ }^{45}$ & VMPT (vs VTP) & $206 / 260$ & $41 \%$ (vs $37 \%)$ & - & $40 \%$ & $81 \%$ \\
\hline GIMEMA: Palumbo et $\mathrm{al}^{46}$ & VMPT (vs VMP) & $354 / 393$ & $39 \%$ CR (vs $21 \%$ ) & $16 \%$ & $32 \%$ & $87 \%$ \\
\hline
\end{tabular}

Abbreviations: VGPR, very good partial remission; VMP, bortezomib, melphalan, prednisone; MP, melphalan, predisone; VMPT, bortezomib, melphalan, prednisone, thalidomide; VTP, bortezomib, thalidomide, prednisone; VAD, vincristine, adriamycin, doxorubicin; PAD, bortezomib, doxorubicin, dexamethasone; VTD, velcade, thalidomide, dexamethasone; TD, thalidomide, dexamethasone; VBMCP, BCNU, vincristine, melphalan, prednisone; VBAD, vincristine, BCNU, doxorubicin, dexamethasone.

transplant - with its attendant mortality, morbidity, and cost.

While the details of the various bortezomib based front line regimens are beyond the scope of this review, a summary of the responses noted to date are shown in Table 5. With the understanding that response rates in single/few institution phase II studies are typically higher than those obtained in phase III multi-institutional settings, a regimen that stands out is bortezomib, lenalidomide, and dexamethasone (VRD). With 65 evaluable patients, the combination of bortezomib, lenalidomide, and dexamethasone resulted in a $100 \%$ response rate and a $38 \% \mathrm{CR} / \mathrm{nCR}$ rate.$^{50} \mathrm{~A}$ caveat of course, is that lenalidomide based induction regimens often result in inadequate stem cell harvests with granulocyte colony stimulating factor (GCSF) mobilization and therefore require cyclophosphamide or the recently FDA-approved CXCR inhibitor, plerixafor, to ensure adequate stem cell harvests.

\section{Mechanism of action of bortezomib}

While rational drug design and pharmacodynamic assays identified and confirmed the proteasome as the biologic target, without an understanding of the exact mechanism of

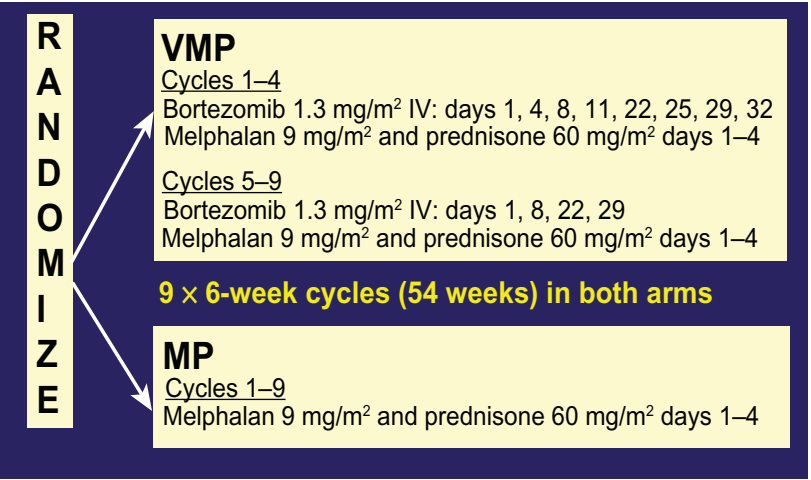

Figure 6 Chemotherapy schedule of bortezomib, melphalan, and prednisone (VMP) and melphalan and prednisone (MP) in the VISTA trial.

Abbreviations: VMP, velcade, melphalan, prednisone; MP, melphalan, prednisone. action, the full therapeutic potential of proteasome inhibition cannot be realized. Research has focused on three possible themes that will be discussed below: the transcription factor $\mathrm{NF}-\kappa \mathrm{B}$, the interaction of the pro-apoptotic factor NOXA and the c-myc oncogene, and finally, the transcription factor $\mathrm{x}$-box binding protein 1 (XBP-1) and the unfolded protein response.

Initial focus was on the impact of bortezomib on NF- $\kappa \mathrm{B}$, which promotes tumor cell survival and proliferation. The inhibitor protein $\mathrm{I}-\kappa \mathrm{B}$ binds $\mathrm{NF}-\kappa \mathrm{B}$ in the cytoplasm, thereby rendering NF- $\kappa \mathrm{B}$ inactive. A variety of cytokines and other cellular stimuli result in the phosphorylation and ubiquitination of $\mathrm{I}-\kappa \mathrm{B}$ by E3 ligase, thus targeting it for proteasome mediated degradation (Figure 7). ${ }^{2}$

Bortezomib, by blocking the latter process, results in increased availability of $\mathrm{I}-\kappa \mathrm{B}$ to inhibit $\mathrm{NF}-\kappa \mathrm{B}$, resulting in the inhibition of tumor cell growth. Gene expression profiling studies in patients with myeloma who responded to bortezomib treatment also highlighted pathways such as $\mathrm{NF}-\kappa \mathrm{B}$ activity and cell adhesion, thereby confirming preclinical studies. ${ }^{69}$

Additional work by Hideshima et al revealed that bortezomib activation seemed to be dependent on the activation of c-Jun NH2-terminal kinase (JNK) and subsequently caspases- 8 and caspase- 3 that elicit DNA damage and apoptosis. In parallel, bortezomib was noted to be associated with the up-regulation of p53. ${ }^{70}$ While these inital studies shed some light on the mechanism of action, it is unclear if the changes observed in NF- $\kappa \mathrm{B}$ and $\mathrm{JNK}$ are a cause or the result of the death process. Indeed, more recent studies suggest the antimyeloma activity of proteasome inhibition is actually p53 independent. ${ }^{71}$

When myeloma cell lines are exposed to bortezomib, the proapoptotic factor NOXA is induced in a concentration dependent manner accompanied by the activation of caspases. NOXA is also induced by p53 and other transcriptional factors such as hypoxia-inducible factor 1 (HIF-1) and E2F-1, consistent 
Table 5 Phase I/II and II combination trials in untreated myeloma

\begin{tabular}{|c|c|c|c|c|c|c|}
\hline Trial & Regimen & $n / N$ & CR/nCR & VGPR & PR & ORR \\
\hline Harousseau et $\mathrm{al}^{51}$ & Vel/Dex & $48 / 52$ & $21 \% \mathrm{CR}$ & $10 \%$ & $35 \%$ & $67 \%$ \\
\hline Corso et $\mathrm{al}^{52}$ & & $54 / 54$ & $50 \%$ & $20 \%$ & $16 \%$ & $86 \%$ \\
\hline Rosinol et al $\left.\right|^{53}$ & Vel alternating with Dex & $40 / 40$ & $13 \% \mathrm{CR}$ & $10 \%$ & $43 \%$ & $65 \%$ \\
\hline Jagannath et a $\left.\right|^{54}$ & Vel \pm Dex & $49 / 49$ & $18 \%$ & $20 \%$ & $49 \%$ & $88 \%$ \\
\hline Orlowski et al ${ }^{55}$ & Vel \pm PLD & $29 / 63$ & $28 \%$ & - & $52 \%$ & $79 \%$ \\
\hline Jakubowiak et al ${ }^{56}$ & VDD & $30 / 30$ & $40 \% \mathrm{CR}$ & $23 \%$ & $30 \%$ & $93 \%$ \\
\hline Palumbo et $\mathrm{al}^{57}$ & & $102 / 102$ & $13 \% \mathrm{CR}$ & $47 \%$ & $36 \%$ & $96 \%$ \\
\hline Belch et $\mathrm{a}^{58}$ & & $50 / 50$ & $18 \%$ & - & $60 \%$ & $78 \%$ \\
\hline Landau et al ${ }^{59}$ & $\mathrm{VDD} \rightarrow \mathrm{TD}$ & $3|/ 3|$ & $29 \%$ & $10 \%$ & $42 \%$ & $81 \%$ \\
\hline Wang et $a^{160}$ & VTD & $38 / 38$ & $16 \%$ & - & $71 \%$ & $87 \%$ \\
\hline Kaufman et $\mathrm{al}^{61}$ & & $34 / 34$ & $27 \% \mathrm{CR}$ & $32 \%$ & $35 \%$ & $94 \%$ \\
\hline Yoon et al ${ }^{62}$ & $\mathrm{VAD} \rightarrow \mathrm{VTD}$ & $55 / 71$ & $51 \%$ & $10 \%$ & $35 \%$ & $96 \%$ \\
\hline Richardson et al ${ }^{50}$ & VRD & $65 / 68$ & $38 \%$ & $30 \%$ & $25 \%$ & $100 \%$ \\
\hline Berenson et $\mathrm{a}^{63}$ & VAM & $31 / 35$ & $16 \% C R$ & $10 \%$ & $13 \%$ & $39 \%$ \\
\hline Bensinger et $\mathrm{a}^{64}$ & $\mathrm{VCD} \rightarrow \mathrm{VTD}$ & $43 / 44$ & $35 \%$ & $21 \%$ & $40 \%$ & $96 \%$ \\
\hline Reeder et $\mathrm{a}^{65}$ & VCD & $33 / 33$ & $39 \%$ & $21 \%$ & $27 \%$ & $88 \%$ \\
\hline Knop et $\mathrm{a}^{66}$ & & $100 / 100$ & II\% CR & - & $68 \%$ & 79 \\
\hline Barlogie et al ${ }^{67,68}$ & VTD-PACE & $480-480$ & - & - & - & NR \\
\hline
\end{tabular}

Abbreviations: PLD, liposomal doxorubicin;VDD,Velcade, liposomal doxorubicin, dex;TD, thalidomide, dexamethasone;VTD, Velcade, thalidomide, dexamethasone;VAD, vincristine, adriamycin, doxorubicin; VRD, Velcade, revlimid dexamethasone; VAM, velcade, arsenic trioxide, melphalan; VCD, Velcade, cyclophosphamide, thalidomide; VDT-PACE, Velcade, dexamethasone, thalidomide, cisplatin, doxorubicin, cyclophosphamide, etoposide.

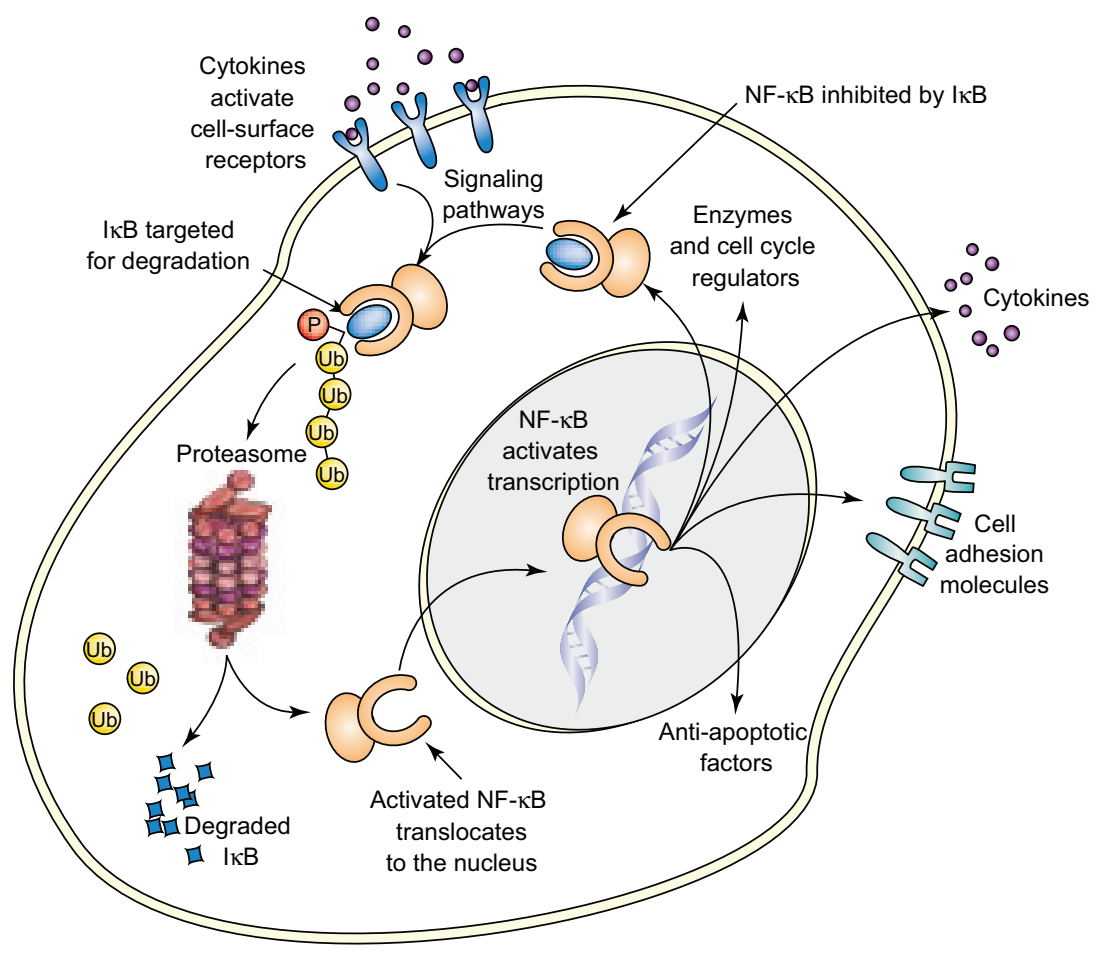

Figure $7 \mathrm{NF}-\kappa \mathrm{B}$ activation pathway. The inhibitor protein $\mathrm{I}-\mathrm{\kappa B}$, when bound to NF- $\mathrm{KB}$ in the cytoplasm, renders NF- $\kappa \mathrm{B}$ inactive. $\mathrm{A}$ variety of cellular stimuli result in the phosphorylation and ubiquitination of $\mathrm{I}-\mathrm{KB}$, thereby targeting it for proteasome mediated degradation. Bortezomib, by inhibiting the proteasome, results in increased $\mathrm{I}-\mathrm{K} \mathrm{B}$ inhibition of NF- $\kappa \mathrm{B}$, thus resulting in inhibition of tumor growth. Reproduced with permission from Adams J. Potential for proteasome inhibition in the treatment of cancer. Drug Discov Today. 2003;8(7):307-315. ${ }^{3}$ Copyright @ 2003 Elsevier. 
with its involvement in the response to many types of cellular stress. Human NOXA contains one BH3 (Bcl-2 homology 3) domain, which has a high affinity for the antiapoptotic factor Mcl-1. Because Mcl-1 is a target for ubiquitination, proteasome inhibition increases levels of Mcl-1. The induction of NOXA is therefore essential to override high Mcl-1 levels and allow for the activation of the apoptotic machinery in response to bortezomib. ${ }^{72}$ Also, NOXA's interaction with anti-apoptotic members of the Bcl-2 family causes release of cytochrome $c$ into the cytosol, leading to the activation of caspases and induction of apoptosis (Figure 8 ). ${ }^{73}$

Bortezomib induction of NOXA is also seen in melanoma and mantle cell lymphoma cell lines, with antisense NOXA oligonucleotide (but not control) resulting in a decrease in bortezomib induced apoptosis. ${ }^{71,74}$ Of note, apoptosis/NOXA induction is not induced by conventional chemotherapeutic agents but is induced by other proteasome inhibitors (eg, MG132), suggesting a possible class specific effect. ${ }^{73,75}$ To understand why NOXA is preferentially induced in tumor cells, the myriad transcription factors with consensus binding sites at the NOXA promoter were restricted to those that are conserved (as NOXA itself is) across mammalian species and also dysregulated by proteasome inhibition and tumorogenesis. The oncogene c-myc emerged as a candidate mediator of tumor specificity. Indeed, when c-myc levels were decreased by RNA interference, the tumor cell-specific induction of NOXA was abrogated. Exogenous c-myc also increased the sensitivity of nonmalignant cells to proteasome inhibition by bortezomib. ${ }^{72}$

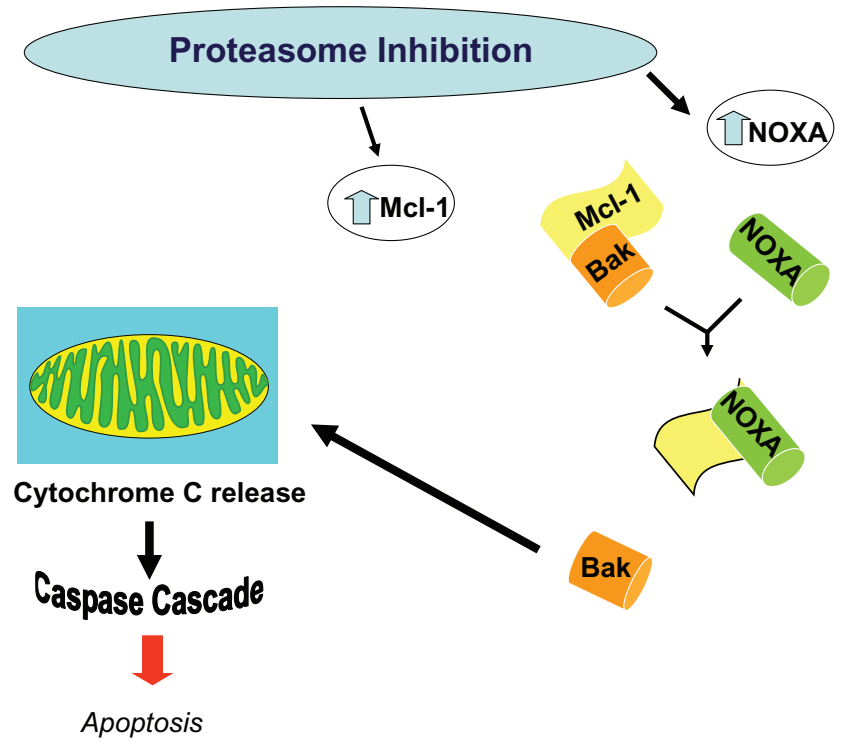

Figure 8 Alteration in levels of $\mathrm{Mcl}-\mathrm{I}$ and NOXA results in apoptosis. Proteasome inhibiton increases levels of the proapoptoic factor NOXA, which then can override the concurrent increase in the anti-apoptic factor Mcl-I, thereby inducing the activation of caspases, and resulting in apoptosis.
The interaction of NOXA and c-myc also provides a possible rationale for the encouraging clinical data noted thus far when histone deacetylase (HDAC) inhibitors are combined with bortezomib. The transcriptional activity of c-myc at the NOXA promoter can be favored by chromatin remodeling or modification proteins (including histone acetyl transferases, with acetylated histone $\mathrm{H} 3$ being a classical cofactor for myc). ${ }^{72}$ HDAC inhibition is also thought to interfere with the targeting of ubiquinated proteins via the aggresome for eventual autophagy/degradation by the lysozome, an alternate pathway to proteasome-mediated degradation. ${ }^{76}$

A third possible explanation for the specificity of bortezomib for myeloma cells is based on the unfolded protein response (UPR). Plasma cells have highly developed rough endoplasmic reticulum (ER) and chaperone proteins that enable them to produce vast quantities of antibodies per second. If misfolded proteins accumulate in ER, the UPR signaling pathway is activated through its sensing mechanism IRE1 $\alpha .{ }^{77}$ The IRE1 kinase, in turn, results in the removal of an intron from the transcription factor $\mathrm{XBP} 1$, resulting in a activated ie, spliced form XBP-1. ${ }^{78}$ Interestingly XBP-1 is is highly expressed in plasma cells and is a prerequisite for transformation from antigen selected B cell to plasma cell.

Once the UPR is activated, the unfolded proteins are refolded by upregulation of the chaperone molecules or destroyed through cytosolic 26S proteasomes; otherwise, accumulation of unfolded protein results in apoptosis of the cell (Figure 9). Proteasome inhibition triggers apoptosis by interfering with the UPR pathway, both at the sensing level as well as by preventing destruction of misfolded protein. ${ }^{79}$

\section{Pathophysiology and management of bortezomib toxicities Thrombocytopenia}

The thrombocytopenia associated with bortezomib therapy has been well characterized. The platelet count drops during Days 1 to 14 and then rapidly recovers to baseline level during Days 15 to 21 (Figure 10). The mean reduction in relapsed/refractory patients is $60 \%$ and appears to be independent of the baseline platelet count, the concentration of the monoclonal protein, and bone marrow plasmacytosis. Murine studies demonstrated no cytotoxic effects on megakaryocytes, thus suggesting a mechanism distinct from traditional myelosuppressive chemotherapeutic agents. ${ }^{80}$ 


\section{Unfolded Protein Response}

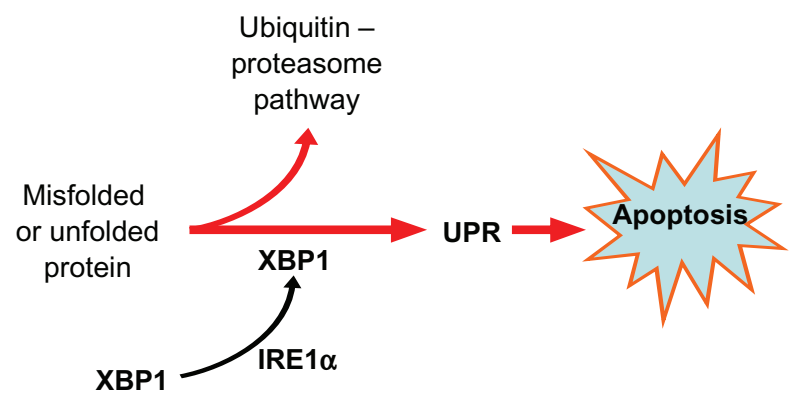

Figure 9 The unfolded protein response. If misfolded proteins accumulate in endoplastic reticulum, the sensing mechanism IREI $\alpha$ activates the transcription factor XBP-I via IREI kinase. XBP-I, in turn, activates the unfolded protein response (UPR) and results in apoptosis.

\section{Neuropathy}

When the proteasome is inhibited, proteins accumulate in aggresomes at the periphery of cells and then track centrally via microtubules towards the microtubule-organizing center (MTOC) ${ }^{81}$ When the distribution of microtubules between polymerized and soluble fractions was compared following the treatment of neuroblastoma and myeloma cells with five proteasome inhibitors, the polymerized fraction increased from $41 \%$ to $68 \%$ to approximately $55 \%$ to $99 \%$, for up to 144 hours after the proteasome inhibitor was removed. Immunofluorescence studies did not reveal microtubule bundles seen with taxanes, suggesting microtubule stabilization occurred by a mechanism different than direct drug binding. ${ }^{82}$ Animal models have also found significant mitochondrial and endoplasmic reticulum damage in dorsal root ganglia. ${ }^{83}$ Other postulated mechanisms of bortezomib associated neuropathy include mitochondrial dysregulation of calcium homeostasis or dysregulation of growth factors important for neuron survival. ${ }^{84}$

Clinically, it is important to note the baseline rate of neuropathy in patients with relapsed/refractory myeloma. In the phase II SUMMIT and CREST studies with bortezomib, $81 \%$ of patients had symptoms by FACT/GOG-Ntx questionnaire and $83 \%$ by neurologists' examination. ${ }^{85}$ This likely reflects not only the side effects of prior treatments, but also a manifestation of the disease itself. While the likelihood of developing severe peripheral neuropathy (PN) was more frequent in those patients with baseline neuropathy, the overall occurrence was independent of baseline neuropathy.

In the phase III APEX trial, of the $37 \%$ of patients who experienced peripheral neuropathy (PN), 9\% had grade $\geq 3$. The neuropathy was typically sensory, although $2 \%$ of patients did experience motor neuropathy. The neuropathy does appear to be dose related with PN typically occurring by cycle 5 and then reaching a plateau by cycle 8 , associated with cumulative bortezomib doses of 26 and $42 \mathrm{mg} / \mathrm{m}^{2}$ respectively ${ }^{86}$ Based on similar findings in previous studies, the APEX trial also incorporated dose-modification guidelines for PN (see Table 5).

Sixty-eight percent of patients in the APEX study who had dose modification for grade $\geq 2$ PN experienced improvement or resolution to baseline in their symptoms at a median of 110 days without any compromise in efficacy. The development of neuropathy was independent of age, prior therapies (including thalidomide and vincristine), and glucose intolerance/diabetes. ${ }^{86}$

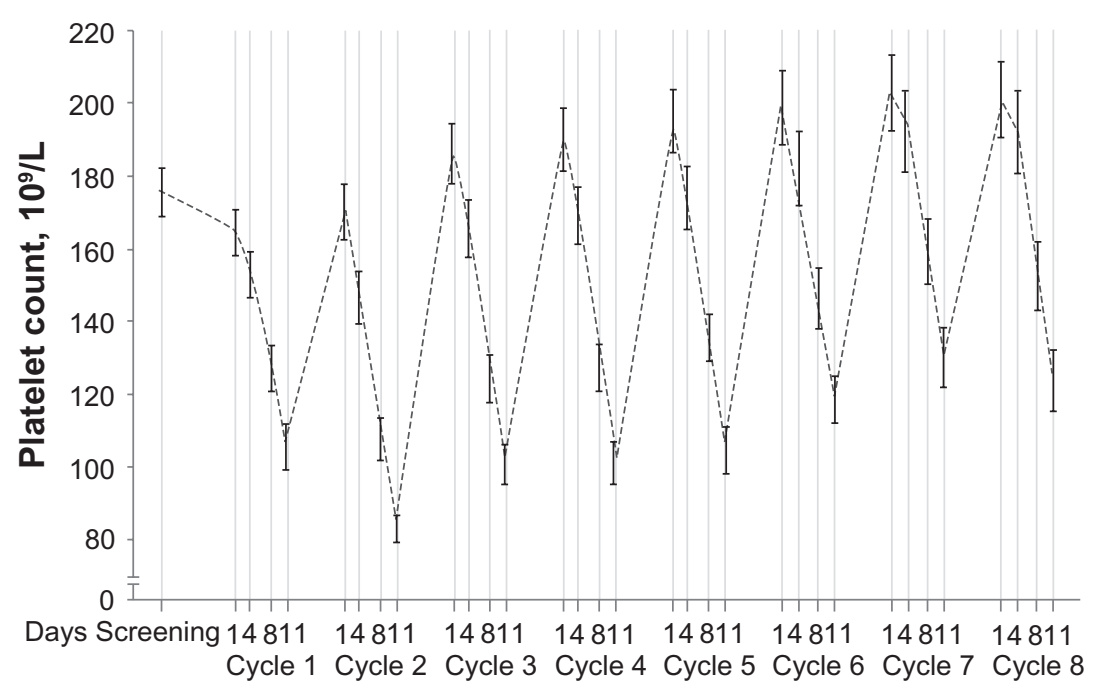

Figure 10 Kinetics of thrombocytopenia associated with bortezomib therapy. Reproduced with permission from Lonial S, Waller EK, Richardson PG, et al. Risk factors and kinetics of thrombocytopenia associated with bortezomib for relapsed, refractory multiple myeloma. Blood. 2005; 106(I2):3777-3784. ${ }^{80}$ Copyright (C) 2005 American Society of Hematololgy. 
Table 6 Recommended dose modification for bortezomib-related neuropathic pain and/or peripheral sensory neuropathy ${ }^{87}$

Severity of peripheral neuropathy signs and symptoms

Grade I (paresthesias and/or loss of reflexes)

Grade I with pain or Grade 2 (interfering with function but not with activities of daily living)

Grade 2 with pain or Grade 3 (interfering with activities of daily living)

Grade 4 (disabling)
Modification of dose and regimen

No action

Reduce bortezomib to $1.0 \mathrm{mg} / \mathrm{m}^{2}$

Withold bortezomib therapy until toxicity resolves. When toxcicity resolves reinitiate with a reduced dose of bortezomib at $0.7 \mathrm{mg} / \mathrm{m}^{2}$ and change treatment schedule to once per week

Discontinue bortezomib

Grading based on NCl Common Toxicity Criteria CTCAE 3.0

A recent publication described a case series of five patients with myeloma who received bortezomib and then developed severe motor involvement. Electrophysiological evaluations showed demyelinating or mixed axonal-demyelinating neuropathy with prominent motor involvement. Cerebrospinal fluid showed albumin-cytological dissociation. Importantly, all four patients treated with either steroids or intravenous immunoglobulin had improved outcomes, suggesting a possible immunologic cause of this neuropathy ${ }^{88}$ Therefore, the development of motor neuropathy merits prompt neurological consultation.

Particularly in the setting of combination therapy, attenuation in the dosing schedule eg, weekly treatment, appears to be associated with significantly less neurotoxicity. For example, the incidence of grade 3 or higher neuropathy with VMP decreased from $14 \%$ to $2 \%$ with twice weekly vs weekly bortezomib with preliminary outcome data showing no loss in efficacy ${ }^{46}$ Interestingly, patients treated with the combination of the heat shock protein (HSP)-90 inhibitor tanesipmycin and bortezomib have not developed Grade 3 PN, suggesting a possible neuroprotective effect of this novel agent. ${ }^{89}$ Of note, development/exacerbation of PN has also not been observed to date with the novel proteasome inhibitor carfilzomib, suggesting that this may not be a class specific effect. ${ }^{90,91}$

Currently there is no proven effective prophylaxis for PN. A variety of agents are used for symptomatic relief of boretzomib associated PN including opioids, tricyclic antidepressants such as nortryptline, anticonvulsants such as gabapentin, serotonin-norepeinephrine reuptake inhibitors such as duloxetine, nonsteroidal anti-inflammatory agents, vitamins, and nutritional supplements such as $\alpha$-lipoic acid, glutamine, and L-carnitine. ${ }^{84}$ However, with recent data suggesting a possible decrease in the efficacy of bortezomib with concomitant vitamin $\mathrm{C}^{92}$ and other supplements such as green tea ${ }^{92}$, neither the effectiveness in symptom palliation nor the absence of an interaction with bortezomib has been clearly established in randomized clinical trials.

\section{The future of proteasome inhibition}

A protein is first identified to be degraded by the polyubqiuitination of lysine residues. The process consists of sequential ubquitin activation, conjugation, and protein ligation - each catalyzed by E1, E2, and E3 enzymes (Figure 11) - which creates the polyubiquitination chain. It appears that there is a family of small ubiquitin like modifiers such as Nedd8, SUMO, FAT10 and ISG15 that are also able to target proteins for degradation. ${ }^{93}$ Each step of this process is therefore a putative therapeutic target. Efforts are underway to evaluate novel agents, with a Nedd8 activating enzyme inhibitor (MLN 4924) already in phase I clinical trials. ${ }^{94}$

Based on the pharmacaphore that interacts with the proteasome's active site, proteasome inhibitors can be divided into five classes: peptide aldehydes, peptide boronotes, peptide vinyl sulfones, peptide epoxyketones, and the only nonpeptide group $-\beta$ lactone inhibitors (Table 6). ${ }^{2}$ The peptide aldehydes such as MG-132 are the first class to be studied and while cell permeable, they are not only rapidly oxidized and unstable, but also lack specificity with activity against nonproteasome enzymes such as serine and cysteine proteases.

The peptide boronates were derived by substitution of the aldehyde with boron to increase potency, selectivity, and stability. ${ }^{2}$ Bortezomib is currently the only FDA approved proteasome inhibitor. Recently published preclinical data demonstrated activity comparable with bortezomib with another peptide boronate compound, CEP-18770, that is also water-soluble and orally bioavailable. ${ }^{95}$ Bortezomib is also being used as a platform for phase I/II studies with numerous novel agents including an anti-IL6 antibody, heat shock protein inhibitors, and epigenetic modulators such as vorinostat or panobinostat. These novel agents may therefore shed light on mechanisms of bortezomib resistance. For example, in two different studies, three patients who were refractory to bortezomib had a response to bortezomib with the addition of a novel agent - either tanespimycin or vorinostat. ${ }^{89,96}$ 

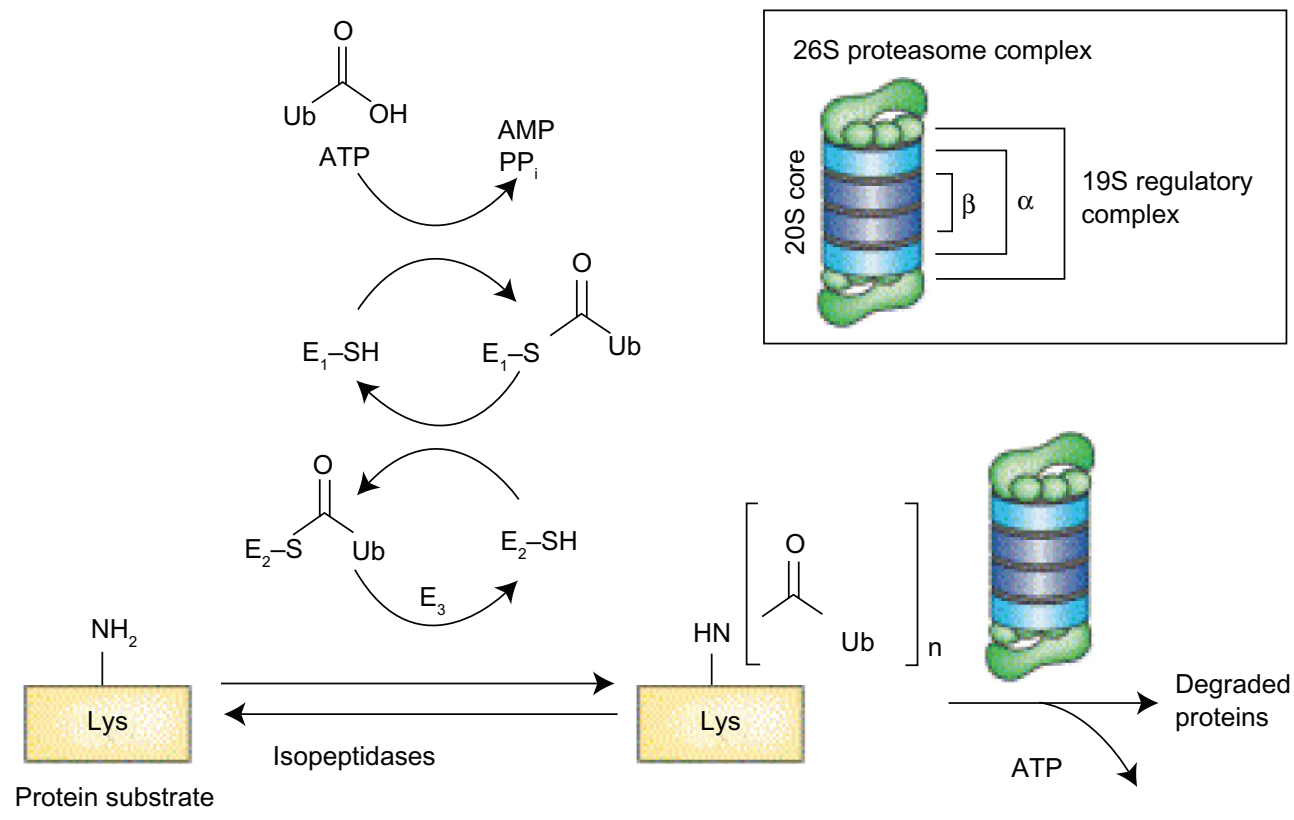

Protein substrate

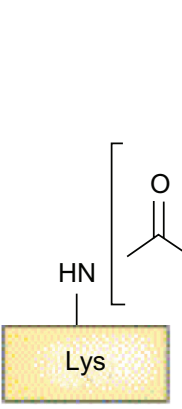

s

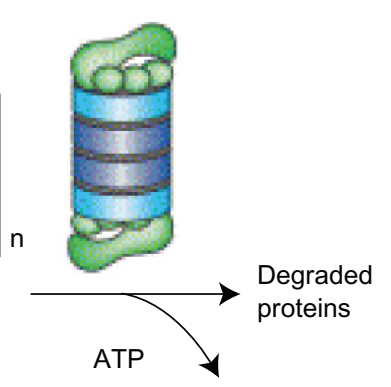

$\mathrm{Ub}$

Figure I I Protein ubiquitination that earmarks proteins for proteasome degradation requires three classes of enzymes: EI for activation of ubiquitin, E2 carrier protein for conjugation, and finally the E3 ligase that transfers ubiquitin to a lysine residue on the target protein. Reproduced with permission from Adams J. Potential for proteasome inhibition in the treatment of cancer. Drug Discov Today. 2003;8(7):307-315. ${ }^{3}$ Copyright @ 2003 Elsevier.

There have been some recent developments in the epoxyketone class of proteasome inhibitors. Epoxomicin is a natural compound initially isolated from an Actinomycete strain and found to have antimelanoma activity in preclinical models. ${ }^{97}$ Carfilzomib (formerly PR-171; Proteolix ${ }^{\circledR}$ ), is a tetrapeptide epoxyketone related to epoxomicin. There are two components of this agent, a peptide portion that binds to the substrate binding pocket(s) of the proteasome with high affinity and a epoxyketone pharmacophore that interacts with the catalytic amino-terminal threonine residue and irreversibly inhibits proteasome activity. Relative to bortezomib, carfilzomib more selectively inhibits the chymotrypsin-like activity of the proteasome with less cross-reactivity at the caspase-like and trypsin-like sites. At doses of $15 \mathrm{mg} / \mathrm{m}^{2}$ or greater, there is $>80 \%$ proteasome inhibition in both red blood cells and peripheral blood mononuclear cells in humans. The ability to give this drug safely on consecutive days allows for sustained proteasome inhibition. ${ }^{98}$ Preliminary data presented at the annual meeting of American Society of

Table 7 Classes of proteasome inhibitors

\begin{tabular}{ll}
\hline Class & Compounds \\
\hline Peptide aldehydes & MGI32 \\
Peptide boronates & Bortezomib, CEP-I8770 \\
Peptide vinyl sulfones & \\
$\begin{array}{l}\text { Peptide epoxyketones } \\
\beta \text { lactone inhibitors }\end{array}$ & Epoxomicin, carfilzomib \\
\hline
\end{tabular}

Hematology in 2008 from ongoing phase II studies indicate an overall response rate of greater than $50 \%$ and $26 \%$ in bortezomib-naïve ${ }^{91}$ and bortezomib-exposed ${ }^{90}$ patients with multiple myeloma, respectively. Cyclic thrombocytopenia was also noted but otherwise, the toxicity profile was different from bortezomib - increased creatinine and possible tumor lysis but no significant neuropathy..$^{90,91,99}$

The first member of the $\beta$ lactone class of proteasome inhibition that received attention was derived from lactacystin, produced by Streptomyces. It was highly unstable intracellularly but was more specific than the peptide aldehydes. ${ }^{2}$ Salinosporamide A (NPI-0052), a product of a marine actinomycete Salinispora tropica, has a bicyclic ring structure similar to lactacystin, but with various substitutions. ${ }^{100}$ Preclinical studies have shown that unlike bortezomib, NPI-0052 inhibits all three protease activities of the proteasome. It is also orally bioactive, a more potent inducer of apoptosis in myeloma cells than bortezomib, and demonstrates activity in bortezomib resistant cell lines as well. ${ }^{101}$ Preliminary reports from ongoing phase I studies in a variety of tumors indicate that the drug appears to be well tolerated. ${ }^{102-104}$

The development of the first-in-class proteasome inhibitor bortezomib in multiple myeloma is a paradigm for the optimal interaction between the pharmaceutical industry, academic institutions, and patient advocacy groups. With ever increasing knowledge of the mechanism of action of 
this agent, the full therapeutic potential of this growing class of drugs can be realized.

\section{Disclosure}

Ajai Chari and Amitabha Mazumder have both received honoraria related to speakers' bureau activities from Millennium Pharmaceuticals Inc., The Takeda Oncology Company. Sundar Jagannath has received honoraria related to Advisory Board Consultancy from Millennium Pharmaceuticals Inc., The Takeda Oncology Company.

\section{References}

1. Adams J. The proteasome: a suitable antineoplastic target. Nat Rev Cancer. 2004;4(5):349-360.

2. Orlowski RZ, Stinchcombe TE, Mitchell BS, et al. Phase I trial of the proteasome inhibitor PS-341 in patients with refractory hematologic malignancies. J Clin Oncol. 2002;20(22):4420-4427.

3. Adams J. Potential for proteasome inhibition in the treatment of cancer. Drug Discov Today. 2003;8(7):307-315

4. Sanchez-Serrano I. Success in translational research: lessons from the development of bortezomib. Nat Rev Drug Discov. 2006;5(2):107-114.

5. Adams J, Palombella VJ, Sausville EA, et al. Proteasome inhibitors: a novel class of potent and effective antitumor agents. Cancer Res. 1999;59(11):2615-2622.

6. Hideshima T, Richardson $\mathrm{P}$, Chauhan D, et al. The proteasome inhibitor PS-341 inhibits growth, induces apoptosis, and overcomes drug resistance in human multiple myeloma cells. Cancer Res. 2001;61(7):3071-3076.

7. LeBlanc R, Catley LP, Hideshima T, et al. Proteasome inhibitor PS-341 inhibits human myeloma cell growth in vivo and prolongs survival in a murine model. Cancer Res. 2002;62(17):4996-5000.

8. Lightcap ES, McCormack TA, Pien CS, Chau V, Adams J, Elliott PJ. Proteasome inhibition measurements: clinical application. Clin Chem. 2000;46(5):673-683.

9. Richardson PG, Barlogie B, Berenson J, et al. A phase 2 study of bortezomib in relapsed, refractory myeloma. $N$ Engl $\mathrm{J} \mathrm{Med}$. 2003;348(26):2609-2617.

10. Richardson PG, Sonneveld P, Schuster MW, et al. Bortezomib or highdose dexamethasone for relapsed multiple myeloma. $N \mathrm{Engl} \mathrm{J} \mathrm{Med}$. 2005;352(24):2487-2498.

11. Richardson PG, Sonneveld P, Schuster M, et al. Extended follow-up of a phase 3 trial in relapsed multiple myeloma: final time-to-event results of the APEX trial. Blood. 2007;110(10):3557-3560.

12. Lee SJ, Richardson PG, Sonneveld P, et al. Bortezomib is associated with better health-related quality of life than high-dose dexamethasone in patients with relapsed multiple myeloma: results from the APEX study. Br J Haematol. 2008;143(4):511-519.

13. San-Miguel JF, Richardson PG, Sonneveld P, et al. Efficacy and safety of bortezomib in patients with renal impairment: results from the APEX phase 3 study. Leukemia. 2008;22(4):842-849.

14. Zangari M, Esseltine D, Lee CK, et al. Response to bortezomib is associated to osteoblastic activation in patients with multiple myeloma. Br J Haematol. 2005;131(1):71-73.

15. Giuliani N, Morandi F, Tagliaferri S, et al. The proteasome inhibitor bortezomib affects osteoblast differentiation in vitro and in vivo in multiple myeloma patients. Blood. 2007;110(1):334-338.

16. Terpos E, Sezer O, Croucher P, Dimopoulos MA. Myeloma bone disease and proteasome inhibition therapies. Blood. 2007;110(4):1098-1104.

17. Zangari M, Esseltine D, Cavallo F, et al. Predictive value of alkaline phosphatase for response and time to progression in bortezomib-treated multiple myeloma patients. Am J Hematol. 2007;82(9):831-833.

18. Ma MH, Yang HH, Parker K, et al. The proteasome inhibitor PS-341 markedly enhances sensitivity of multiple myeloma tumor cells to chemotherapeutic agents. Clin Cancer Res. 2003;9(3):1136-1144.
19. Orlowski RZ, Nagler A, Sonneveld P, et al. Randomized phase III study of pegylated liposomal doxorubicin plus bortezomib compared with bortezomib alone in relapsed or refractory multiple myeloma: combination therapy improves time to progression. J Clin Oncol. 2007;25(25): 3892-3901.

20. Berenson JR, Yang HH, Vescio RA, et al. Safety and efficacy of bortezomib and melphalan combination in patients with relapsed or refractory multiple myeloma: updated results of a phase $1 / 2$ study after longer follow-up. Ann Hematol. 2008;87(8):623-631.

21. Popat R, Oakervee H, Williams C, et al. Bortezomib, low-dose intravenous melphalan, and dexamethasone for patients with relapsed multiple myeloma. Br J Haematol. 2009;144(6):887-894.

22. Pineda-Roman M, Zangari M, van Rhee F, et al. VTD combination therapy with bortezomib-thalidomide-dexamethasone is highly effective in advanced and refractory multiple myeloma. Leukemia. 2008;22(7):1419-1427.

23. Reece DE, Piza G, Trudel S, et al. A Phase I-II Trial of Bortezomib Plus Oral Cyclophosphamide and Prednisone for Relapsed/Refractory Multiple Myeloma. ASH Annual Meeting Abstracts. 2006;108(11):3536.

24. Kropff M, Bisping G, Schuck E, et al. Bortezomib in combination with intermediate-dose dexamethasone and continuous low-dose oral cyclophosphamide for relapsed multiple myeloma. Br J Haematol. 2007;138(3):330-337.

25. Hajek R, Zahradova L, Gregora E, et al. The reduced intensity Cvd regimen: a good option with well balanced efficacy/toxicity ratio for elderly patients with poor status performance. ASH Annual Meeting Abstracts. 2008 November 16;112(11):3699.

26. Lee SS, Suh C, Kim BS, et al. Bortezomib, doxorubicin and dexamethasone (PAD) combination therapy followed by thalidomide and dexamethasone (TD) as a salvage treatment for relapsed multiple myeloma (MM): preliminary analysis of efficacy and safety. $A S H$ Annual Meeting Abstracts. 2007;110(11):2731.

27. Palumbo A, Gay F, Bringhen S, et al. Bortezomib, doxorubicin and dexamethasone in advanced multiple myeloma. Ann Oncol. 2008;19(6):1160-1165.

28. Richardson P, Jagannath S, Jakubowiak A, et al. Lenalidomide, bortezomib, and dexamethasone in patients with relapsed or relapsed/refractory multiple myeloma (MM): encouraging response rates and tolerability with correlation of outcome and adverse cytogenetics in a phase II study. ASH Annual Meeting Abstracts. 2008;112(11):1742.

29. Poenisch W, Bourgeois M, Wang SY, et al. Bortezomib in combination with bendamustine and prednisone in the treatment of patients with refractory/relapsed multiple myeloma. ASH Annual Meeting Abstracts. 2007;110(11):2723.

30. Palumbo A, Ambrosini MT, Benevolo G, et al. Bortezomib, melphalan, prednisone, and thalidomide for relapsed multiple myeloma. Blood. 2007;109(7):2767-2772.

31. Terpos E, Heath DJ, Zervas K, Dimopoulos MA. The effect of bortezomib monotherapy and bortezomib-based regimens on bone metabolism in patients with relapsed/refractory multiple myeloma. Paper presented at: Haematologica, 2007.

32. Ciolli S, Leoni F, Casini C, Breschi C, Santini V, Bosi A. The addition of liposomal doxorubicin to bortezomib, thalidomide and dexamethasone significantly improves clinical outcome of advanced multiple myeloma. Br J Haematol. 2008;141(6):814-819.

33. Kim YK, Lee JJ, Sohn SK, et al. Clinical Efficacy of VEL-CTD (bortezomib, cyclophosphamide, thalidomide, and dexamethasone) regimen in patients with relapsed or refractory multiple myeloma: a phase II study. ASH Annual Meeting Abstracts. 2008;112(11):3693.

34. San Miguel JF, Schlag R, Khuageva NK, et al. Bortezomib plus melphalan and prednisone for initial treatment of multiple myeloma. $\mathrm{NEngl}$ J Med. 2008;359(9):906-917.

35. Cavo M, Tacchetti P, Patriarca F, et al. Superior complete response rate and progression-free survival after autologous transplantation with up-front velcade-thalidomide-dexamethasone compared with thalidomide-dexamethasone in newly diagnosed multiple myeloma. ASH Annual Meeting Abstracts. 2008;112(11):158.

36. Harousseau J. Updated results: Randomized phase III IFM trial comparing Vel/Dex with VAD induction in MM in pts $\leq 65$ years. Joint ASH/ ASCO Symposium. 2008 December. 
37. Sonneveld P, van der Holt B, Schmidt-Wolf IGH, et al. First analysis of HOVON-65/GMMG-HD4 randomized phase III trial comparing bortezomib, adriamycine, dexamethasone (pad) vs vad as induction treatment prior to high dose melphalan (HDM) in patients with newly diagnosed multiple myeloma (MM). ASH Annual Meeting Abstracts. 2008;112(11):653.

38. Chanan-Khan A, Sonneveld P, Schuster MW, et al. Analysis of herpes zoster events among bortezomib-treated patients in the phase III APEX study. J Clin Oncol. 2008;26(29):4784-4790.

39. Vickrey E, Allen S, Mehta J, Singhal S. Acyclovir to prevent reactivation of varicella zoster virus (herpes zoster) in multiple myeloma patients receiving bortezomib therapy. Cancer. 2009;115(1):229-232.

40. Pour L, Adam Z, Buresova L, et al. Varicella-zoster virus prophylaxis with low-dose acyclovir in patients with multiple myeloma treated with bortezomib. Clin Lymphoma Myeloma. 2009;9(2):151-153.

41. Asahi T, Tsutsui M, Wakasugi M, et al. Valacyclovir neurotoxicity: clinical experience and review of the literature. Eur $J$ Neurol. 2009;16(4):457-460.

42. Hellden A, Lycke J, Vander T, Svensson JO, Odar-Cederlof I, Stahle L. The aciclovir metabolite CMMG is detectable in the CSF of subjects with neuropsychiatric symptoms during aciclovir and valaciclovir treatment. J Antimicrob Chemother. 2006;57(5):945-949.

43. Marin M, Guris D, Chaves SS, Schmid S, Seward JF. Prevention of varicella: recommendations of the Advisory Committee on Immunization Practices (ACIP). MMWR Recomm Rep. 2007 Jun 22;56(RR-4):1-40.

44. Miguel JFS, Schlag R, Khuageva NK, et al. Updated follow-up and results of subsequent therapy in the phase III VISTA trial: bortezomib plus melphalan-prednisone versus melphalan-prednisone in newly diagnosed multiple myeloma. ASH Annual Meeting Abstracts. 12008;112(11):650.

45. Mateos MV, Oriol A, Martinez J, et al. Bortezomib (Velcade)-melphalanprednisone (VMP) versus velcade-thalidomide-prednisone (VTP) in elderly untreated multiple myeloma patients: which is the best partner for velcade: an alkylating or an immunomodulator agent? ASH Annual Meeting Abstracts. 2008;112(11):651.

46. Palumbo A, Bringhen S, Rossi D, et al. A prospective, randomized, phase III study of bortezomib, melphalan, prednisone and thalidomide (VMPT) versus bortezomib, melphalan and prednisone (VMP) in elderly newly diagnosed myeloma patients. ASH Annual Meeting Abstracts. 12008;112(11):652.

47. Rosinol L, Cibeira MT, Martinez J, et al. Thalidomide/dexamethasone (TD) vs bortezomib(Velcade(R))/thalidomide/dexamethasone (VTD) vs $\mathrm{VBMCP} / \mathrm{VBAD} / \mathrm{Velcade}(\mathrm{R})$ as induction regimens prior autologous stem cell transplantation (ASCT) in younger patients with multiple myeloma (MM): first results of a prospective phase III PETHEMA/ Gem trial. ASH Annual Meeting Abstracts. 2008;112(11):654.

48. Attal M, Harousseau JL, Facon T, et al. Single versus double autologous stem-cell transplantation for multiple myeloma. $N$ Engl J Med. 2003;349(26):2495-2502

49. Cavo M, Tosi P, Zamagni E, et al. Prospective, randomized study of single compared with double autologous stem-cell transplantation for multiple myeloma: Bologna 96 clinical study. J Clin Oncol. 2007;25(17):2434-2441.

50. Richardson P, Lonial S, Jakubowiak A, et al. Lenalidomide, bortezomib, and dexamethasone in patients with newly diagnosed multiple myeloma: encouraging efficacy in high risk Groups with updated results of a phase I/II study. ASH Annual Meeting Abstracts. 2008;112(11):92.

51. Harousseau JL, Attal M, Leleu X, et al. Bortezomib plus dexamethasone as induction treatment prior to autologous stem cell transplantation in patients with newly diagnosed multiple myeloma: results of an IFM phase II study. Haematologica. 2006;91(11):1498-1505.

52. Corso A, Barbarano L, Mangiacavalli S, et al. Bortezomib with HIG-dose dexamethasone as first Line therapy in patients with multiple myeloma candidates to high-dose therapy. ASH Annual Meeting Abstracts. 2007;110(11):3595.

53. Rosinol L, Oriol A, Mateos MV, et al. Phase II PETHEMA trial of alternating bortezomib and dexamethasone as induction regimen before autologous stem-cell transplantation in younger patients with multiple myeloma: efficacy and clinical implications of tumor response kinetics. J Clin Oncol. 2007;25(28):4452-4458.
54. Jagannath S, Durie BGM, Wolf JL, et al. Long-term follow-up of patients treated with bortezomib alone and in combination with dexamethasone as frontline therapy for multiple myeloma. ASH Annual Meeting Abstracts. 2006;108(11):796.

55. Orlowski RZ, Peterson BL, Sanford B, et al. Bortezomib and pegylated liposomal doxorubicin as induction therapy for adult patients with symptomatic multiple myeloma: Cancer and Leukemia Group B Study 10301. ASH Annual Meeting Abstracts. 2006;108(11):797.

56. Jakubowiak A, Kendall $\mathrm{T}$, Al-Zoubi A, et al. Initial treatment with bortezomib (Velcade(R)), Doxil(R), and dexamethasone (VDD) is superior to thalidomide and dexamethasone (TD) as initial therapy prior to autologous stem cell transplantation (ASCT) for multiple myeloma (MM). ASH Annual Meeting Abstracts. 2008;112(11):3713.

57. Palumbo A, Falco P, Gay F, et al. Bortezomib-doxorubicin-dexamethasone as induction prior to reduced intensity autologous transplantation followed by lenalidomide as consolidation/maintenance in elderly untreated myeloma patients. ASH Annual Meeting Abstracts. 2008;112(11):159.

58. Belch A, Reece DE, Bahlis NJ, et al. Bortezomib [VELCADETM], pegylated liposomal doxorubicin [DOXIL/CAELYX(R)] and dexamethasone in the treatment of previously untreated multiple myeloma patients: impact on quality-of-life. ASH Annual Meeting Abstracts. 2007;110(11):3618.

59. Landau H, Hassoun $\mathrm{H}$, Cohen A, et al. Sequential administration of bortezomib, liposomal doxorubicin and dexamethasone (BDD) followed by thalidomide and dexamethasone (td) results in rapid control of untreated high-risk multiple myeloma (MM) and improves depth of response. ASH Annual Meeting Abstracts. 2008;112(11):3712.

60. Wang M, Giralt S, Delasalle K, Handy B, Alexanian R. Bortezomib in combination with thalidomide-dexamethasone for previously untreated multiple myeloma. Hematology. 2007;12(3):235-239.

61. Kaufman JL, Gleason C, Heffner L, Lonial S. Bortezomib, thalidomide, and dexamethasone as induction therapy for patients with symptomatic multiple myeloma. ASH Annual Meeting Abstracts. 2007;110(11):3605.

62. Yoon SS, Kim HJ, Chung JS, et al. Sequential VAD (Vincristine, adriamycin, dexamethasone) and VTD (Bortezomib, thalidomide, dexamethasone) induction followed by high-dose therapy with autologous stem cell transplantation and maintenance treatment with bortezomib for newly diagnosed multiple myeloma: final analysis of phase II trial. ASH Annual Meeting Abstracts. 2008;112(11):3330.

63. Berenson JR, Yellin O, Woytowitz D, et al. Bortezomib, ascorbic acid and melphalan (bam) therapy for patients (pts) with newly diagnosed multiple myeloma (MM): an effective and well-tolerated frontline regimen. ASH Annual Meeting Abstracts. 2007;110(11):3602.

64. Bensinger W, Jagannath S, Vescio R, et al. A phase II study of bortezomib (Velcade (R)), cyclophosphamide (Cytoxan (R)), thalidomide (Thalomid(R)) and dexamethasone as first-line therapy for multiple myeloma. ASH Annual Meeting Abstracts. 2008;112(11):94.

65. Reeder CB, Reece DE, Kukreti V, et al. Cyclophosphamide, bortezomib and dexamethasone induction for newly diagnosed multiple myeloma: high response rates in a phase II clinical trial. Leukemia. 2009.

66. Knop S, Liebisch P, Wandt H, et al. Bortezomib, intravenous cyclophosphamide and dexamethasone (VelCD) for previously untreated multiple myeloma: an interim analysis of the German DSMM XIa Trial. ASH Annual Meeting Abstracts. 2008 November 16;112(11):2776.

67. Barlogie B, Anaissie EJ, Shaughnessy JD Jr, et al. Ninety percent sustained complete response $(\mathrm{CR})$ rate projected 4 years after onset of $\mathrm{CR}$ in gene expression profiling (GEP)-defined low-risk multiple myeloma (MM) treated with total therapy 3 (TT3): basis for GEP-risk-adapted TT4 and TT5. ASH Annual Meeting Abstracts. 2008;112(11):162.

68. Barlogie B, Anaissie E, van Rhee F, et al. Incorporating bortezomib into upfront treatment for multiple myeloma: early results of total therapy 3 . Br J Haematol. 2007;138(2):176-185.

69. Mulligan G, Mitsiades C, Bryant B, et al. Gene expression profiling and correlation with outcome in clinical trials of the proteasome inhibitor bortezomib. Blood. 2007;109(8):3177-3188.

70. Hideshima T, Mitsiades C, Akiyama M, et al. Molecular mechanisms mediating antimyeloma activity of proteasome inhibitor PS-341. Blood. 2003;101(4):1530-1534. 
71. Qin JZ, Ziffra J, Stennett L, et al. Proteasome inhibitors trigger NOXAmediated apoptosis in melanoma and myeloma cells. Cancer Res. 2005;65(14):6282-6293.

72. Nikiforov MA, Riblett M, Tang WH, et al. Tumor cell-selective regulation of NOXA by c-MYC in response to proteasome inhibition. Proc Natl Acad Sci U S A. 2007;104(49):19488-19493.

73. Jullig M, Zhang WV, Ferreira A, Stott NS. MG132 induced apoptosis is associated with p53-independent induction of pro-apoptotic NOXA and transcriptional activity of beta-catenin. Apoptosis. 2006;11(4):627-641.

74. Perez-Galan P, Roue G, Villamor N, Montserrat E, Campo E, Colomer D The proteasome inhibitor bortezomib induces apoptosis in mantle-cell lymphoma through generation of ROS and Noxa activation independent of p53 status. Blood. 2006;107(1):257-264.

75. Fernandez Y, Verhaegen M, Miller TP, et al. Differential regulation of NOXA in normal melanocytes and melanoma cells by proteasome inhibition: therapeutic implications. Cancer Res. 2005;65(14):6294-6304.

76. Hideshima T, Bradner JE, Wong J, et al. Small-molecule inhibition of proteasome and aggresome function induces synergistic antitumor activity in multiple myeloma. Proc Natl Acad Sci U S A. 2005;102(24):8567-8572.

77. Davenport EL, Moore HE, Dunlop AS, et al. Heat shock protein inhibition is associated with activation of the unfolded protein response pathway in myeloma plasma cells. Blood. 2007;110(7):2641-2649.

78. Lee AH, Iwakoshi NN, Anderson KC, Glimcher LH. Proteasome inhibitors disrupt the unfolded protein response in myeloma cells. Proc Natl Acad Sci U S A. 2003;100(17):9946-9951.

79. Obeng EA, Carlson LM, Gutman DM, Harrington WJ Jr, Lee KP, Boise LH. Proteasome inhibitors induce a terminal unfolded protein response in multiple myeloma cells. Blood. 2006;107(12):4907-4916.

80. Lonial S, Waller EK, Richardson PG, et al. Risk factors and kinetics of thrombocytopenia associated with bortezomib for relapsed, refractory multiple myeloma. Blood. 2005;106(12):3777-3784.

81. Johnston JA, Ward CL, Kopito RR. Aggresomes: a cellular response to misfolded proteins. J Cell Biol. 1998;143(7):1883-1898.

82. Poruchynsky MS, Sackett DL, Robey RW, Ward Y, Annunziata C, Fojo T. Proteasome inhibitors increase tubulin polymerization and stabilization in tissue culture cells: a possible mechanism contributing to peripheral neuropathy and cellular toxicity following proteasome inhibition. Cell Cycle. 2008;7(7):940-949.

83. Cavaletti G, Gilardini A, Canta A, et al. Bortezomib-induced peripheral neurotoxicity: a neurophysiological and pathological study in the rat. Exp Neurol. 2007;204(1):317-325.

84. Argyriou AA, Iconomou G, Kalofonos HP. Bortezomib-induced peripheral neuropathy in multiple myeloma: a comprehensive review of the literature. Blood. 2008;112(5):1593-1599.

85. Richardson PG, Briemberg H, Jagannath S, et al. Frequency, characteristics, and reversibility of peripheral neuropathy during treatment of advanced multiple myeloma with bortezomib. J Clin Oncol. 2006;24(19):3113-3120.

86. Richardson PG, Sonneveld P, Schuster MW, et al. Reversibility of symptomatic peripheral neuropathy with bortezomib in the phase III APEX trial in relapsed multiple myeloma: impact of a dose-modification guideline. Br J Haematol. 2009;144(6):895-903.

87. Millennium Pharmaceuticals I. VelcadeTM (bortezomib) for injection. Prescribing information. Cambridge, MA Millennium Pharmaceuticals, Inc.; 2005 .

Biologics: Targets \& Therapy

\section{Publish your work in this journal}

Biologics: Targets \& Therapy is an international, peer-reviewed journal focusing on the patho-physiological rationale for and clinical application of Biologic agents in the management of autoimmune diseases, cancers or other pathologies where a molecular target can be identified. This journal is indexed on PubMed Central, CAS,
88. Ravaglia S, Corso A, Piccolo G, et al. Immune-mediated neuropathies in myeloma patients treated with bortezomib. Clin Neurophysiol. 2008;119(11):2507-2512.

89. Richardson PG, Chanan-Khan A, Lonial S, et al. Tanespimycin (T) + bortezomib (BZ) in multiple myeloma (MM): confirmation of the recommended dose using a novel formulation. ASH Annual Meeting Abstracts. 2007;110(11):1165.

90. Jagannath S, Vij R, Stewart AK, et al. Initial results of PX-171-003, an open-label, single-arm, phase II study of carfilzomib (CFZ) in patients with relapsed and refractory multiple myeloma (MM). ASH Annual Meeting Abstracts. 2008;112(11):864.

91. Vij R, Wang M, Orlowski R, et al. Initial results of PX-171-004, an open-label, single-arm, phase II study of carfilzomib (CFZ) in patients with relapsed myeloma (MM). ASH Annual Meeting Abstracts. 2008;112(11):865.

92. Perrone G, Hideshima T, Ikeda H, et al. Ascorbic acid inhibits antitumor activity of bortezomib in vivo. Leukemia. 2009.

93. Yang Y, Kitagaki J, Wang H, Hou DX, Perantoni AO. Targeting the ubiquitin-proteasome system for cancer therapy. Cancer Sci. 2009;100(1):24-28.

94. Soucy TA, Smith PG, Milhollen MA, et al. An inhibitor of NEDD8activating enzyme as a new approach to treat cancer. Nature. 2009;458(7239):732-736.

95. Piva R, Ruggeri B, Williams M, et al. CEP-18770: A novel, orally active proteasome inhibitor with a tumor-selective pharmacologic profile competitive with bortezomib. Blood. 2008;111(5):2765-2775.

96. Weber D, Badros AZ, Jagannath S, et al. Vorinostat plus bortezomib for the treatment of relapsed/refractory multiple myeloma: early clinical experience. ASH Annual Meeting Abstracts. 2008;112(11):871.

97. Hanada M, Sugawara K, Kaneta K, et al. Epoxomicin, a new antitumor agent of microbial origin. J Antibiot (Tokyo). 1992;45(11):1746-1752.

98. Demo SD, Kirk CJ, Aujay MA, et al. Antitumor activity of PR-171, a novel irreversible inhibitor of the proteasome. Cancer Res. 2007;67(13):6383-6391.

99. Alsina M, Trudel S, Vallone M, Molineaux C, Kunkel L, Goy A. Phase 1 single agent antitumor activity of twice weekly consecutive day dosing of the proteasome inhibitor carfilzomib (PR-171) in hematologic malignancies. ASH Annual Meeting Abstracts. 2007;110(11):411.

100. Feling RH, Buchanan GO, Mincer TJ, Kauffman CA, Jensen PR, Fenical W. Salinosporamide A: a highly cytotoxic proteasome inhibitor from a novel microbial source, a marine bacterium of the new genus salinospora. Angew Chem Int Ed Engl. 2003;42(3):355-357.

101. Chauhan D, Catley L, Li G, et al. A novel orally active proteasome inhibitor induces apoptosis in multiple myeloma cells with mechanisms distinct from bortezomib. Cancer Cell. 2005;8(5):407-419.

102. Hamlin PA, Aghajanian C, Hong D, et al. First-in-human phase 1 dose escalation study of NPI-0052, a novel proteasome inhibitor, in patients with lymphoma and solid tumor. ASH Annual Meeting Abstracts. 2008;112(11):4939.

103. Price T, Padrik P, Townsend A, et al. Clinical trial of NPI-0052 (2nd generation proteasome inhibitor) in patients having advanced malignancies with expanded RP2D cohorts in lymphoma and CLL. ASH Annual Meeting Abstracts. 2008;112(11):4934.

104. Richardson P, Hofmeister CC, Zimmerman TM, et al. Phase 1 clinical trial of NPI-0052, a novel proteasome inhibitor in patients with multiple myeloma. ASH Annual Meeting Abstracts. 2008;112(11):2770.

\section{Dovepress}

EMBase, Scopus and the Elsevier Bibliographic databases. The manuscript management system is completely online and includes a very quick and fair peer-review system, which is all easy to use. Visit http://www.dovepress.com/testimonials.php to read real quotes from published authors. 